ARQueOlogía Y SOCIEDAD

№ 31, 2016: 65-92

ISSN: 0254-8062

RECIBIDO: ABRIL DE 2016

ACEPTADO: MAYO DE 2016

\title{
INSTRUMENTOS MUSICALES PRECOLOMBINOS: LA "ANTARA" O LA FLAUTA DE PAN ANDINA EN EL FORMATIVO FINAL (300 A.C.) E INTERMEDIO TEMPRANO (100.C.) ${ }^{1}$
}

\author{
CARLOS D. SÁNCHEZ HUARINGA \\ Universidad Nacional Mayor de San Marcos \\ KARLOS_202@HOTMAIL.COM
}

HAY TANTA MÚSICA EN EL MUNDO QUE ES RAZONABLE SUPONER QUE LA MÚSICA COMO EL LENGUAJE Y POSIBLEMENTE LA RELIGIÓN, ES UN RASGO ESPECÍFICO DE NUESTRA ESPECIE. (BALCKING 1973, 2006)

\section{RESUMEN}

La música en el Perú prehispánico, del periodo de crecimiento regional o también llamado del Intermedio Temprano es representado principalmente por las sociedades Mochica y Nazca y significa también el máximo desarrollo de los instrumentos musicales basados en los aerófonos más simbólicos del mundo andino: las flautas de pan (antaras) y las “quenas”. Así, los Mochicas habrían conocido (¿inventado?) la flauta de Pan dual complementaria y la sociedad Nazca, las "antaras" en juego separadas por mitades (distancia de octavas) además de una técnica inigualable en cerámica para la elaboración de estos instrumentos.

Palabras clave: Música, aerófonos, flautas de pan, antaras, siku, zampoñas.

\section{Abstract}

Music in pre-Hispanic Peru, from the period of regional growth or also called the Early Intermediate is represented mainly by the Mochica and Nazca societies and also means the maximum development of the musical instruments based on the most symbolic aerophones of the Andean world: the flutes of Bread (antaras) and "quenas". Thus, the Mochicas would have known (invented?) The complementary dual Pan flute and the Nazca society, the "antaras" in play separated by halves (octave distance) in addition to an unequaled technique in ceramics for the elaboration of these instruments.

KEY wORDs: Music, aerophones, flutes of bread, antaras, siku, zampoñas.

1. El presente es una continuación del artículo publicado en la Revista Arqueología y Sociedad № 29 del MAAUNMSM bajo el título: "Los primeros instrumentos musicales precolombinos: La flauta de Pan andina o la antara". 


\section{La "Época de oro" de las Flautas de Pan o "Antaras" Andinas}

Por la cantidad, calidad y simbolismos de los restos iconográficos y materiales encontrados, se puede deducir rápidamente que se trata de la época de esplendor de la flauta de Pan andina peruana, llamada comúnmente "antara"2. Se habría iniciado con la sociedad Paracas de la costa del sur peruano y con la sociedad Vicús del norte; los dos de finales del periodo Formativo. ${ }^{3}$

Este gran desarrolló sucedió en la costa peruana de acuerdo a los vestigios arqueológicos, zonas que en algún momento dejaron de contar con tradiciones musicales de flautas de pan después de haber visto florecer las más diversas flautas de pan de los cuales aún sobreviven algunos modelos como las flautas de pan individuales (o antaras propiamente) y las "duales complementarias" o sikus (aunque ya no en la costa peruana). Precisaremos resumidamente cuatro casos y caracteres muy relevantes en la historia de la flauta de pan andina en este tiempo:

\section{La "Antara Compleja” de Paracas}

Morfológicamente se trata de un modelo de flauta de Pan muy peculiar (figs. 1,2 y 3), fue construida (inventada) por esta sociedad del Periodo Formativo y confeccionada sólo en cerámica. Se caracteriza por poseer a lo largo o extensión del tubo de la zampoña, dos o más diámetros (tubos "discontinuos"), formando una especie de "bulbo" centímetros después de la embocadura o más hacia el centro, terminando finalmente en punta. César Bolaños llamó a estos modelos "pteforme", "pteromorfo", o de tubos fusiformes o bulbosiformes (estrecho en los extremos y ancho en el medio, tipo "ala de ave"): "El modelo Paracas, de cerámica, se identifica por su perfil pteforme, de morfología tubular cilindro-fusiforme y por sus embocaduras, que son ásperas al deslizar los labios” (Bolaños 1988: 12).

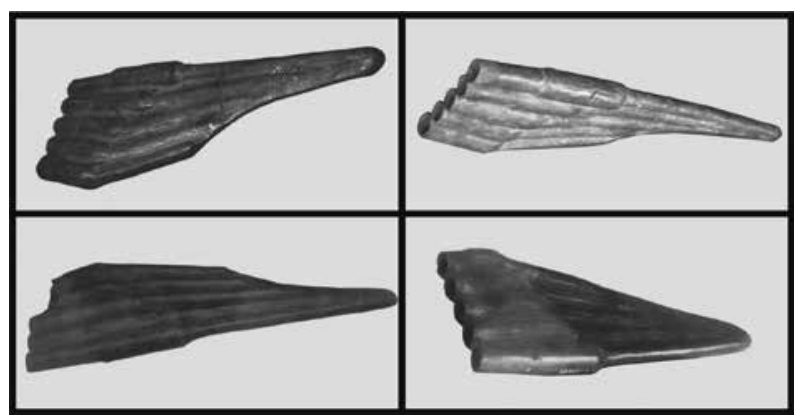

Fig. 1) Flautas de Pan de Paracas de modelos pteroformes, bulbosiformes, fusiformes o de "tubos complejos", se pueden encontrar rastros de estos hasta mediados de la sociedad Nazca y se extiende por el sur hasta zonas que hoy pertenecen a Bolivia, Argentina y Chile.

2. Usamos el entrecomillado en el término "antara", toda vez que no es la denominación académica exacta o pertinente, sino, es un término coloquial o popular que incluso los arqueólogos lo han usado de manera arbitraria, su denominación académica sería "flautas de Pan", de las cuales, una de las tantas variantes, sería la antara: La flauta de Pan (421.112 en la clasificación de Hornbostel \& Sachs) es un aerófono o instrumento de viento compuesto por un número variable de tubos (o, en ciertos casos conductos) de distintas longitudes y grosores, generalmente cerrados por un extremo y abiertos o semi-abiertos por el otro. En su extremo proximal, tales tubos pueden ser lisos o poseer biseles simples o dobles; dependiendo de tamaños y cumpliendo los principios acústicos que rigen el sonido de este tipo de elementos (Fletcher 2005), los distintos tubos que componen el aerófono proporcionan diferentes notas y, mediante el empleo de ciertos recursos interpretativos, una serie de variables de armónicos. (Civallero 2012: 40). 
Este sugestivo modelo que desaparece con el surgimiento de las "clásicas antaras" Nazca de tubos uniformes, generó al parecer una gran tradición que se expandió hacia el lado sur peruano: en el altiplano se encuentra este modelo en la cultura Yura (Gerard: 2004, 2013), en Argentina y en Chile (cultura Aconcagua y otros), tradiciones que habrían sobrevivido hasta la actualidad en instrumentos como la pifilca o la flauta de chino en Chile. Pero la influencia de este modelo también llegó a culturas de la costa y sierra norte como Salinar (fig. 3), posiblemente entre los Mochicas (fig. 3) y Recuay (Bolaños 2007: 84).

Pérez de Arce (Chile) y Arnaud Gerard (Bolivia) coinciden en señalar que la búsqueda de un tipo exclusivo de sonoridad andina empujó a la aparición de este sugestivo modelo y que esta "búsqueda sonora" continuaría luego con la invención de los "resonadores", expresión también del sonido "rajado" (Pérez de Arce) o del sonido "tara” (Arnaud Gerard) ${ }^{4}$. En esta misma dirección podemos entender la existencia de los silbatos y algunas flautas "bifónicas" que emiten obviamente dos sonidos paralelos teniendo una sola embocadura y que existen prácticamente en todas las culturas del Formativo en adelante.

Fig. 2) Flautas de Pan de "tubos complejos", se muestra en cada uno de ellos sus diseños internos: 2a) Paracas (Perú, estudiado por Bolaños), $2 b$ y c) Aconcagua y Mapuche (Bolivia, estudiados por Pérez de Arce) y 3c) Yura (Bolivia, estudiado por Gerard).

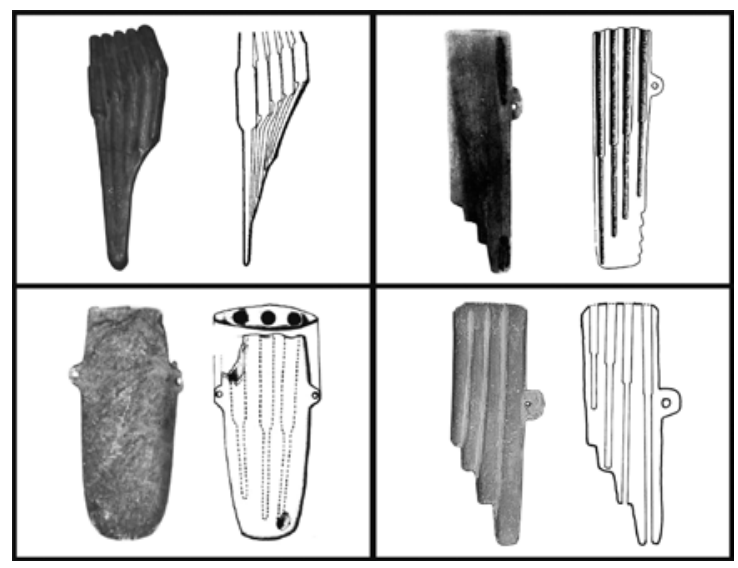

4. José Pérez de Arce denomina a este modelo de antaras "de tubos complejos" por el carácter ya descrito. Nos dice que la razón de ser fue la búsqueda de un tipo particular de sonoridad, al que denomina "sonido rajado", sonido que luego se conseguiría también con el uso de los "tubos resonadores". Este tipo de sonoridad es definido por Pérez de Arce como "extremadamente fuerte, intenso, y enérgicamente disonante". Este mismo tipo de sonoridad estudiado en las "siringas" y otros aerófonos bolivianos por Arnaud Gerard (2013) y recogiendo la denominación de "sonido tara" de Stobart (1966), nos dice "extraño sonido multifónico con redoble (...) una estética sonora vibrante, pulsante, disonante, y multifónica muy dominante en los Andes centrales y meridionales de ayer y hoy.". Ciertamente se trata de un tipo de sonoridad andina muy peculiar que ha sobrevivido hasta la actualidad a pesar de la imposición de un tipo de sonoridad occidental de supuesta mayor "afinación" y "limpieza". La denominación de "tubos complejos" y "sonido rajado" se propone estudiando a las pifilcas prehispánicas en el caso de Chile con Pérez de Arce y en el caso boliviano se propone el "sonido tara" a partir del estudio de los conjuntos de pinkillus de carnaval por Stobart, retomado por Gerard. De las características de estos aerófonos es traspolado al siku buscando un mejor entendimiento del carácter y razón de ser de los "resonadores". Este tipo de sonoridad ("profundamente andina"), los encontramos o sobrevive en la actualidad por ejemplo: en los conjuntos de tarkas en el altiplano, en los conjuntos de pifilcas y de flautas de chino en Chile, en las flautas "roncadoras" en la sierra norte peruana, en los conjuntos de wapululus, lawa k'umus, chaqalladas y otros del altiplano peruano, en los conjuntos de pinkuyllus de Cusco y de pinkillus de Potosí (Bolivia) y finalmente en los mismos conjuntos de sikuris altiplánicos, en su forma de tocar como "rajando" los tubos de los sikus y el efecto sonoro que aportan estos "resonadores" o filas secundarias adheridas a las filas principales. 


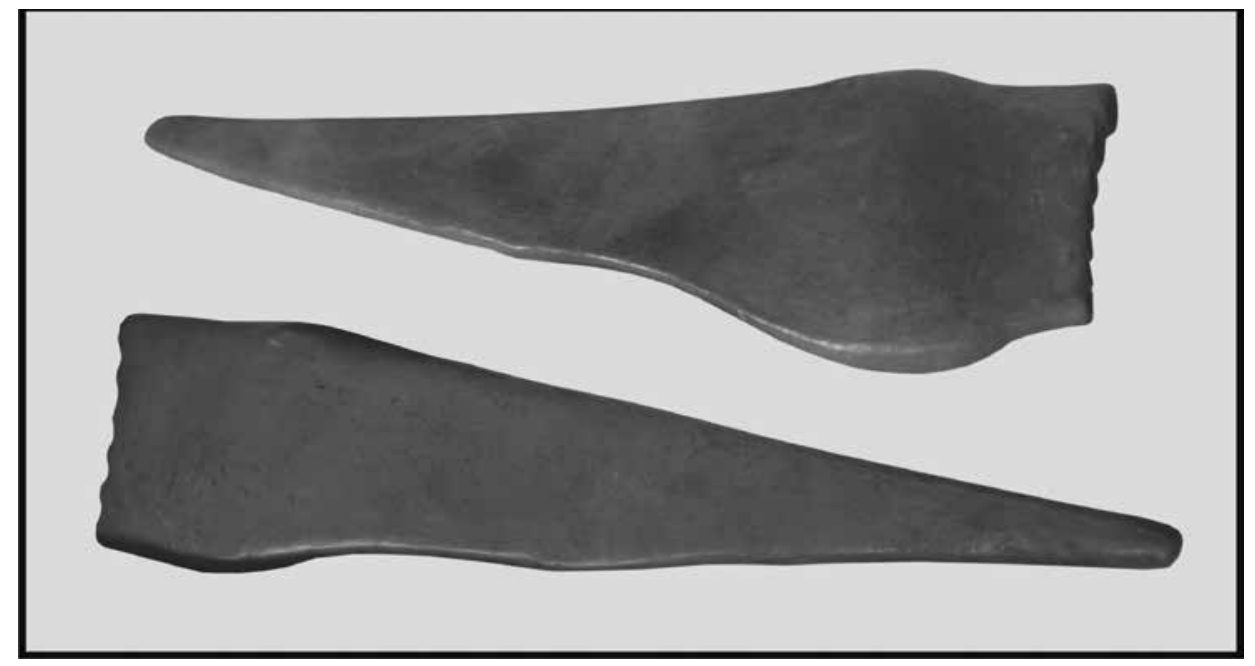

Fig. 3) Flautas de pan de modelos "pteroformes" o de "tubos complejos": 3a) Flauta de Pan Salinar (MNAAHP). 3b) Flauta de Pan Mochica (Museo Casinelli).

\section{Los "Resonadores" de las "Antaras" Paracas}

Desde algún momento de la época prehispánica la flauta de pan adquiere una fila más de tubos adjunto a la principal, a estos se le conoce como "hileras o filas secundarias", se trata de una fila de tubos no usadas por el músico (no tañidas, no tocadas) ${ }^{5}$. Este sería el inicio de lo que actualmente son los "sikus" altiplánicos, caracterizados justamente por el uso de la hilera secundaria a la cual denominan popularmente "resonadores" debido a su posible funcionalidad inmediata ("resonar") otorgándoles un peculiar tipo de sonoridad. Esto justamente diferencia a las flautas de pan de modelo siku (que llevan estos "resonadores") frente a las antaras (que no llevan estos "resonadores" o "hileras secundarias"). ${ }^{6}$

La hilera secundaria morfológicamente puede ser idéntica a la hilera principal o más pequeña que esta (generalmente "afinadas" a una escala superior), pero siempre va adherida a esta fijamente. No tiene función musical aparente (no se toca) pero se le responsabiliza de una modificatoria sonora en la dirección de "resonar" el sonido que emite el tubo tañido. Las discusiones sobre estos "resonadores" han girado y giran en torno a su razón de ser (¿Para qué fue inventado?) y sobre la acción y resultante sonora, es decir, sobre su funcionalidad, sus características sonoras y físicas. De hecho, todos coinciden que el objetivo principal es alterar el sonido de la flauta de pan en el que

5. Esta particularidad de los sikus (variedad de las flautas de Pan andinas), ha sido objeto de muchos e inacabados estudios: Hornbostel y Sachs 1914; Mead 1903; Vega 1946; Izikowitz 1934; González-Bravo 1948; Langevin 1992, Girault 1968, Baumann 1982; d'Harcourt 1925, Pérez de Arce 1992, Gerard 1999; Valencia 1982; 1989a; 1989 b y otros.

6. Los sikus tienen una gran multiplicidad o tipos de "hileras secundarias" que reciben también diferentes denominaciones dependiendo de las localidades y de sus posibles razones de ser o funciones: Así, son llamados carga en algunas zonas urbanas de Perú, chala en el norte de Argentina, haylli en Taquile (Puno, Perú), falsos, ch'usa, sirinu, sanq'a, marimacho, shallka, orko (Gerard 1999), phallqa, serena, siruni (Gutiérrez 2009) en algunos lugares de Bolivia y falsa (pues no se toca) también en ciertos lugares del altiplano peruano en épocas pasadas. 
actúan ("armonizar", "mejorar", "diferenciar" o “enriquecer"). Pérez de Arce y Langevin señalan que la razón de los "resonadores" (desde el tiempo pre hispánico), es la búsqueda constante de una sonoridad exclusiva o particular. Américo Valencia presenta a los "resonadores" en términos de "enriquecimiento musical": "Los tubos de la hilera secundaria enriquecen los sonidos producidos por los tubos de la hilera principal por la adición de armónicos pares. Estos reciben parte del soplido dirigido a los tubos principales, y emiten sonidos cuyas fundamentales son una octava de los sonidos producidos por los tubos principales". (Valencia 1989: 35). Xavier Bellenguer (2007), tomando versiones de los sikuris de Taquile (Puno, Perú), nos dice que el fin de los "resonadores" es contribuir "al enriquecimiento armónico de cada sonido producido soplando en los tubos de la primera hilera", y cita la opinión de un fabricante de sikus en Taquile: "La segunda hilera se llama haylli, le da un bonito sabor, es su acompañante" (p. 140). Arnaud Gerard (1999: 103) nos dice que la función de la segunda hilera es modificar la sonoridad que puede producir una flauta de pan simple: "Una parte del flujo aerodinámico destinado al tubo principal le alcanza y le hace sonar en subrégimen, de tal manera que las series de sobre tonos de ambos tubos se suman...". Finalmente, en nuestra experiencia etnográfica encontramos que la hilera secundaria ciertamente le cambia el timbre a las flautas de pan logrando cierta sonoridad "multifónica", "disonante", "bifónica”, "pastoso", “mezclado", “desigual”, “borroso", "vibrante”, “armónica”, etc.

Por otro lado, algunos investigadores, sugieren que el origen de las hileras secundarias o "resonadores", se encuentran en las "antaras" de "tubos complejos" de la cultura Paracas del periodo Formativo (Pérez de Arce 1993; Haberli 1972; Bolaños 1988; Gerard 1999)7, pero que como tal, se le puede ver claramente recién en el Intermedio Tardío. César Bolaños (2007) nos señala que flautas de pan con "resonadores" las encontramos en las culturas Chincha, Chancay, Pachacámac y Collao. Sin embargo Pérez de Arce nos señala que estos aparecen en el Horizonte Medio, con la cultura Wari (600 - 1200 d.C.) "Cuando decae la antara y surge el siku" (proponiendo que la diferenciación del siku respecto de la "antara" sería justamente la existencia del "resonador"). Luego hace la siguiente aseveración: "La solución acústica del tubo resonador es similar a la del tubo complejo, y se utiliza dentro de un mismo esquema musical. Siendo anterior este último, resulta lógico pensar que durante la sustitución cultural entre Nazca y Wari se debió producir el traspaso del sistema acústico desde el tubo complejo de la antara al resonador del siku" (1993: 479). Por su parte, Isabel Aretz (1991: 51) señala que "Con los Chincha que aparecen en la costa sur aproximadamente en 1200 d.C., (y que son) ejecutantes de kenas y antaras, aparecen las antaras de dos hileras de tubos...".

Nosotros señalamos, respaldados en la flauta de pan Paracas, que el conocimiento de la "hilera resonante" ya está presente hacia el final del periodo Formativo, "conviviendo" con los "tubos complejos" de la misma sociedad (fig. 2). Esta pequeña flauta de pan Paracas construida con huesos de pelícano (pelecanus erythrorhynchos) (6425/MNAAHP), presenta dos hileras de tubos prácticamente idénticos, atados en un solo amarro, lo que significa que era tañida sujetando a la vez las dos hileras a la vez y con la posibilidad de que la hilera secundaria haya estado cerrada en su base inferior. Es claramente una flauta de Pan con "resonador".

7. Pérez de Arce señala que los constructores de la cultura Paracas inventaron el "tubo complejo". Y luego este invento comenzó un viaje en el tiempo, el espacio y las culturas, encontrándose posteriormente en Nazca, Tiwanaku, San Pedro de Atacama, Diaguitas, Aconcagua y sur de Chile (por ejemplo la flauta del baile de chinos). 


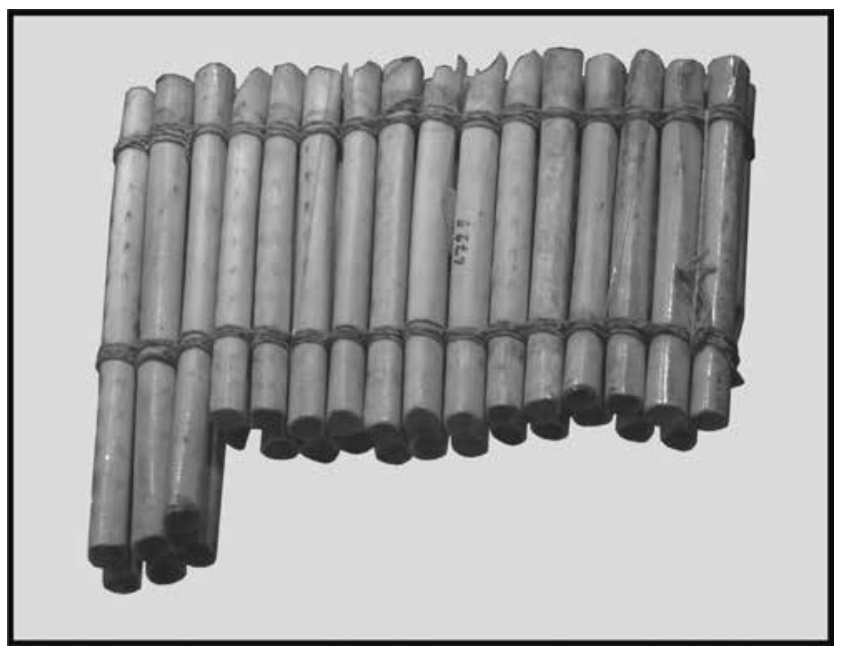

Fig. 4) Flauta de pan Paracas (6425/MNAAHP), presenta una hilera de tubos adherido a la principal de igual morfología al que en la actualidad se le conoce comúnmente como "resonadores".

Ciertamente los modelos de flautas de pan con "resonadores" tienen una clara presencia en el periodo de los Estados Regionales o Intermedio Tardío, con mayor énfasis en los sectores Kollas (aymaras) del sur (fig. 5c). Entonces empezaron a ser construidos masiva y exclusivamente en carrizos o "cañas" (phragmites australis, arundo donax) en desmedro de las flautas de pan fabricados en cerámica por los Paracas y refinado por los Nazcas. En este periodo tardío por ejemplo tendremos una flauta de pan Chincha con "resonador" construida en cerámica (caso muy excepcional) muy cercano ya al modelo siku actual. Por ello, en el ocaso de la era prehispánica ya se podrá hacer una clara distinción entre los dos principales modelos de flautas de Pan del mundo andino: el modelo siku y el modelo antara.

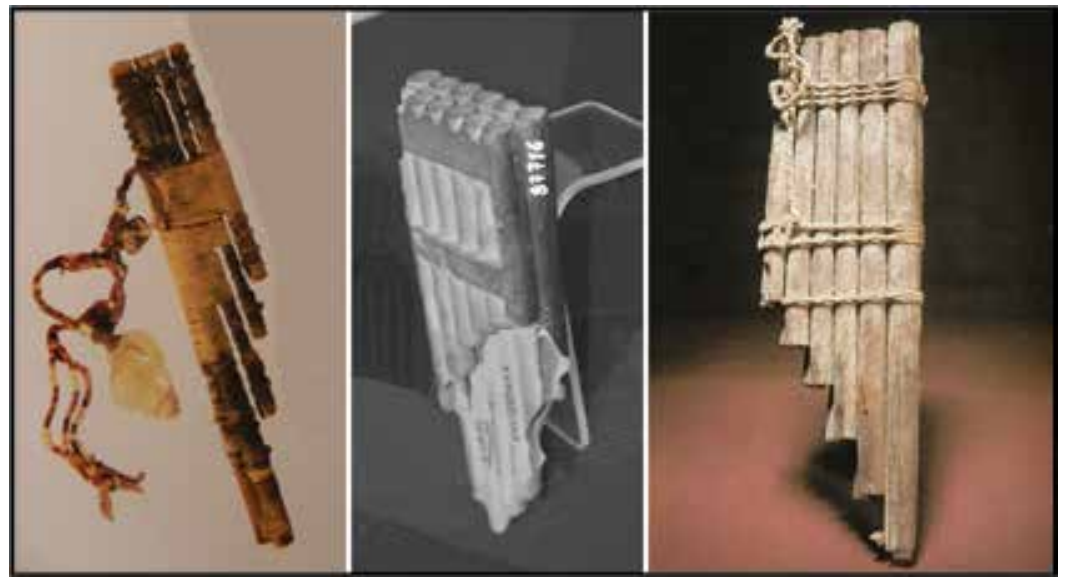

Fig. 5a) "Antara" Nazca construida en "cañas" presenta "resonadores", sería la continuidad de los "resonadores" que viene desde el tiempo Paracas (museo de Zurich, Suiza). 5b) "Antara" Chincha (Intermedio Tardí) con "resonadores" construido en cerámica, ya se conecta con los actuales "sikus" del altiplano pero que en tiempos coloniales existía en toda la costa peruana (MNAAHP). 5c) "Antara" Tiwanaco construido de "cañas", posee "resonadores" como los actuales sikus del altiplano (Museo Contisuyo, Moquegua). 


\section{Las “Antaras" Modelo “w”, “v" Invertida, "Escalera Convergente" o DE "Doble Escalera" DE los Vicús}

Los restos arqueológicos de la sociedad Vicús nos demuestra que conocieron e hicieron uso de un modelo de flauta de pan muy peculiar al que conoceremos debido a su morfología externa como el modelo "W", "V" invertida o en "escalera convergente" (fig. 6 y 10). César Bolaños (2007: 62) sostiene que este tipo de "antara" al desglosarse en dos partes dio lugar a las flautas de pan clásicas de forma "triangular" o de perfil escalerado; sin embargo, sabemos que desde mucho tiempo antes ya las poblaciones norteñas (incluyendo Ecuador), centrales (como Sechín) y sureñas (como Paracas) ya conocían el modelo clásico "triangular".

Este modelo "W" no se expande hacia el sur del continente, salvo en una excepcional situación o casualidad observamos en el altiplano boliviano una flauta de Pan de modelo "W" (siku lo llaman los arqueólogos) construida en piedra de basalto negro proveniente muy posiblemente de tiempos Tiwanacotas estudiado por Fortún (1970) y Bustillos (1989), el hecho de tratarse de una "antara" física posibilitó su estudio organológico ${ }^{8}$.

Finalmente este particular modelo no lograría trascender frente al modelo clásico "triangular" y dejamos de encontrarlo en sociedades de nuestra era posteriores a Vicús, tampoco se han hallado ejemplares de estas flautas de pan, pero si una gran cantidad de representación en cerámica escultórica que testimonia su existencia en el pasado. En el sector norteño, habría llegado a su máximo esplendor en el Periodo de Desarrollo Regional de acuerdo a la arqueología ecuatoriana (500 a.C. - 100 d.c.) pero en adelante y hasta la actualidad prevalece el modelo "intercalado" denominado comúnmente como "rondador". Sin embargo, rezagos de esta fuerte presencia del modelo "W" podemos ver hoy en Colombia con las etnias Kuna y Maku quienes mantienen hasta la actualidad un modelo como el descrito y al cual denominan kamu purrui (fig. 6). Se trata de un modelo eminentemente "norteño" pues lo encontramos con nitidez en culturas ecuatorianas como Chorrera, Jama Coaque, Tolita, y cuya influencia llegó seguramente hasta el norte peruano a sociedades como Vicús.

8. Hace algunos meses, el investigador boliviano Arnaud Gerard ha vuelto a encontrar en colecciones privadas otra flauta de pan del modelo "W", lamentablemente fracturado. Esto podría demostrarnos que en tiempos muy remotos este modelo de "antara" pudo haber sido bastante difundido, futuras investigaciones nos revelarán mayores detalles.

9. La palabra castellana "rondador" es utilizada en tiempos coloniales para re-nombrar a este instrumento de origen prehispánico en toda la zona del Ecuador y Colombia, perdiéndose su denominación oriunda. El término refiere, según los estudiosos ecuatorianos, a un instrumento musical que pertenecía a la gente que hacían las "rondas", una especie de vigilancia rural de los mismos lugareños quienes en su actividad se acompañarían con estos instrumentos musicales. 


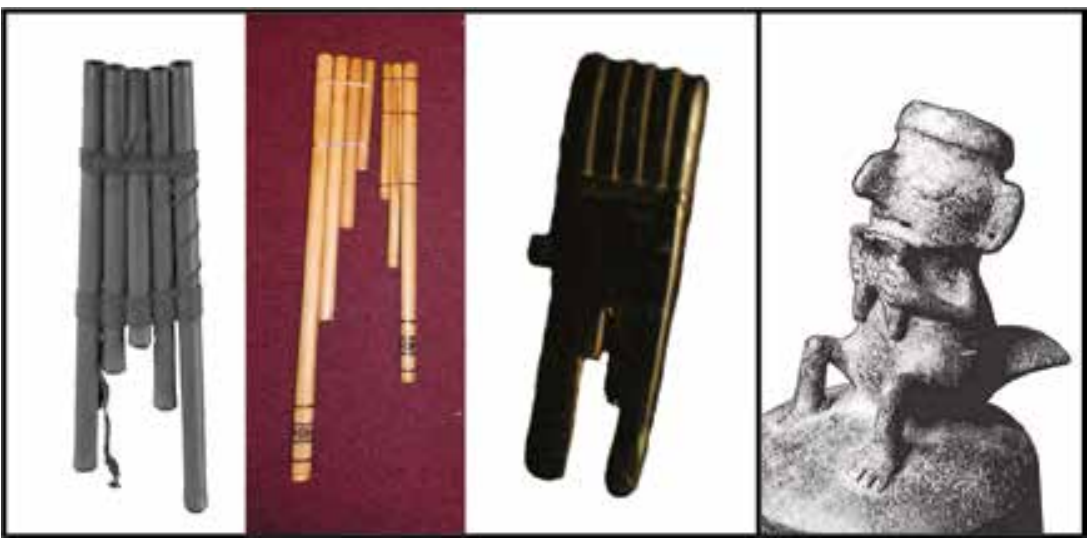

Fig. 6) Flautas de Pan de modelos "W": a) "Antara" de la etnia Maku de Colombia, b) "Antara" de la etnia Kuna, c) "Antara" de piedra del tiempo Tiwanaco d) Músico de la sociedad Vicus (Perú) portando el modelo de "antara" "W".

\section{LAS "ANTARAs" DUALES COMPLEMENTARIAS DE lOS Mochicas}

Los Mochicas nos han heredado una gran cantidad de complejas iconografías cuyos simbolismos aún no se han desentrañado completamente, en ellas se puede ver repetidamente a dos tocadores de flautas de pan los cuales algunas veces van frente a frente o lado a lado y muchas veces una cuerda une los dos instrumentos, esto puede suponer que sería una máxima de la representación de la dualidad en la flauta de pan andina. Este modelo se vería encumbrada en el Intermedio Tardío en la costa peruana y el altiplano peruano donde, a la llegada de los cronistas tendría el nombre de "ayarachic" y luego "siku" y que después de la cruel arremetida cultural hispánica, se han mantenido sólo en el altiplano hasta la actualidad.

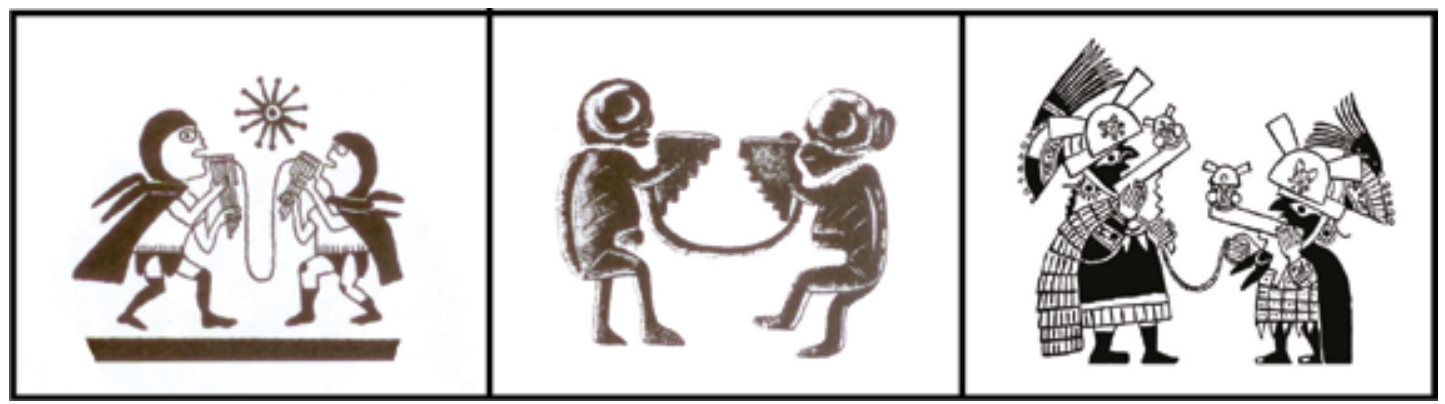

Fig. 7) Iconografías de la sociedad Mochica que representan a dúos de antaristas, sus instrumentos se encuentran ligados con una cuerda (¿Manifestación de la dualidad?) 7a) Tomado de Tello 1938, 7b) Tomado de Hocquenghem 1987, 7c) Tomado de MacClelland y Donnan 2007.

\section{Las “aNTARas" Nazca y las orQuestas musicales}

Esta sociedad, situada en la costa sur del Perú, hizo un profuso uso de flautas de Pan en juegos o familias (varios tamaños), vale decir que orquestaron sus músicas en base a las "antaras" finamente elaboradas en cerámica y acompañadas de membranófonos (bombos) y otros aerófonos (como trompetas y silbatos). En esta sociedad observamos claramente que conocieron con suficiencia los soni- 
dos y sus estructuraciones (músicas) e inventaron posiblemente sistemas musicales muy complejos (Gruszczynska 2014). Por ejemplo construyeron e hicieron uso de "familias o tamaños de antaras" en base al conocimiento de la acústica y las cualidades del sonido (altura, intensidad, timbre y duración), usaron los timbres "medios" y "dobles" (fig. 8), o los sonidos graves y agudos en proporciones exactas (como las octavas), tipos de afinaciones y finalmente hicieron uso de la duplicidad sonora (tocar varios instrumentos semejantes o iguales) con el fin de lograr tipos de sonoridades. Definitivamente si las demás sociedad de los tiempos prehispánicos demostraron sus conocimientos y uso de las flautas de pan vía las iconografías y vasijas escultóricas, la sociedad Nazca nos heredó sus mismas flautas de pan, finamente construidas y en cantidades exorbitantes como para deslumbrarnos.

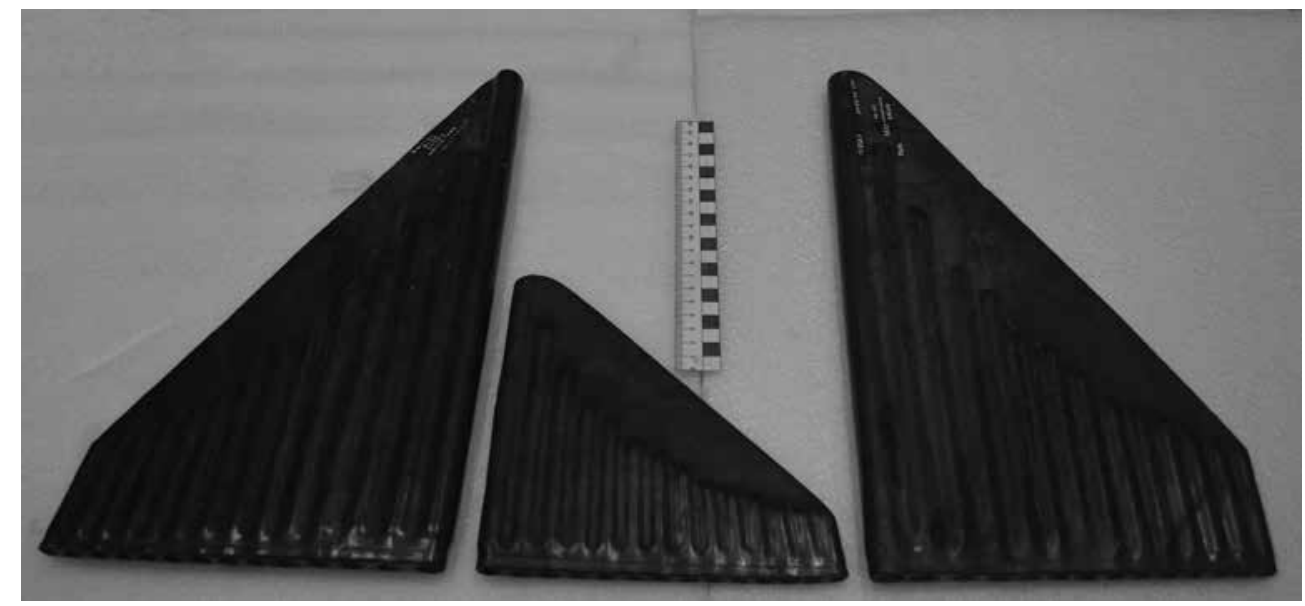

Fig. 8) La sociedad Nazca, manifiesta un alto conocimiento musical al formar orquestas en base al uso de "antaras" de tamaños repetidos y en proporcionalidades ("afinación a la octava"). Este juego o familia de antaras Nazca se encuentran en el Museo de Arqueología de la UNMSM.

\section{LAS FLAUTAS DE PAN EN LAS SOCIEDADES DEL INTERMEDIO TEMPRANO}

Vicús (100 a.C. - 400 d.C.).- Es una de las principales de este periodo, une los finales del formativo con el periodo clásico de las culturas regionales como Mochica y Nazca. Más aún, estamos ante uno de los momentos más significativos dentro del desarrollo histórico de las flautas de pan. Su centro, se sitúa en la costa del norte peruano, en el curso inferior del rio Piura, hoy distrito de Chulucanas, provincia de Morropón, departamento de Piura y se sabe de su interacción con la sociedad Moche inicial así como con las sociedades del norte (hoy Ecuador).

Las botellas silbadoras.- Se observa un profuso uso de las cerámicas conocidas como "botellas o vasijas silbadoras (de agua)", sobre todo las de dos cuerpos, "artefactos sonoros" que llegará hasta las últimas sociedades de la etapa prehispánica como Chancay y Chimú. En Vicús, probablemente haya ocurrido en este sentido una influencia de culturas ecuatorianas como Chorrera (donde se cuenta con vasijas de más de mil años a. C.) con los cuales evidentemente tuvieron mucha relación. Estas vasijas fueron rápidamente catalogadas como "instrumentos musicales" por los arqueólogos por a la sonoridad que emiten debido al silbato que lleva incorporado en su interior y que al contener agua pueden generar sonidos especiales; nosotros creemos que justamente debido a este carácter pueden ser más 
considerados como "silbatos monófonos o bífonos" (fig. 9b). Aun así, nos parece que merece mayor discusión esta determinación conceptual, pero sí indiscutiblemente se trata de un "artefacto sonoro" cuyos momentos de expresividad sonora no necesariamente puedo haber sido la generación de "músi$\mathrm{ca}^{\text {" en el sentido estricto }}{ }^{10}$. Sin embargo, nos parece muy sugestivo que en estas vasijas se encuentren representados la mayor cantidad de músicos antaristas y de percusionistas de manera escultórica, generando una integridad entre los responsables de los sonidos en el mundo prehispánico, vale decir, que los ceramistas relacionaron a estas vasijas sonoras con representaciones de evidentes músicos, principalmente pertenecientes a las élites gobernantes por lo que se puede observar a simple vista.

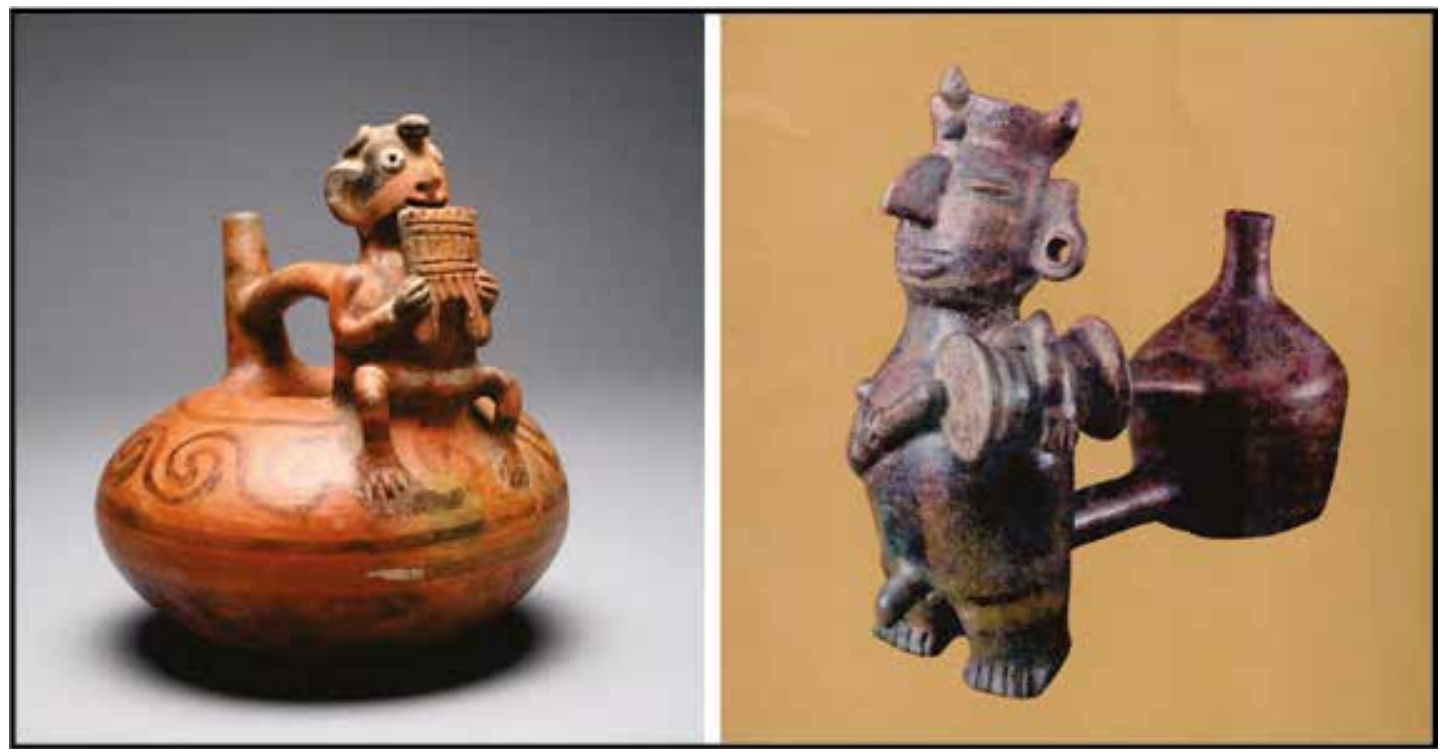

Fig. 9) Los aerófonos y membranófonos en la sociedad Vicús. Se evidencia un prolífico conocimiento de las flautas de pan o "antaras" del modelo " $W$ " (en escalera convergente) y uso de instrumentos percutivos (membranófonos) del modelo cilíndrico o tipo "reloj de arena" (Museo del BCR)

Las flautas de pan Vicús.- Esta sociedad es particularmente interesante por las abundantes evidencias del uso de las flautas de pan de un modelo especial conocido como "W", "V" invertida o "antara en escalera divergente" (Bolaños 2007). Se trata, como observamos en las imágenes, de un modelo que llama la atención poderosamente pues ya no es conocida en la actualidad donde floreció esta sociedad. Organológicamente observamos que este aerófono tiene en los extremos los tubos mayores y va decreciendo hacia su centro, en las imágenes que han sobrevivido de esta sociedad no podemos distinguir el número de tubos y tampoco si este decrecimiento es homogéneo hasta su centro. Como

10. Distinguimos “artefactos sonoros" e "instrumentos musicales": el primero nos ayuda a un mayor agrupamiento de muchos artefactos que emiten sonidos y que no necesariamente son o pueden ser instrumentos musicales propiamente, mientras que el segundo si se refiere exactamente a aquellos artefactos sonoros que han sido inventado y utilizados con la finalidad de hacer música sean estos sean estos melódicos o no. Música a la vez, desde una perspectiva antropológica, la definimos como la combinación de sonidos con sentido o comprensión social producidos mayormente por artefactos sonoros. O como diría Blacking (1973), se trata de "sonidos humanamente organizados". 
podemos observar en las figuras, las evidencias de flautas de Pan de esta cultura que han llegado a nuestros días se encuentran modeladas como parte de decoraciones de las cerámicas o como vasijas escultóricas. Desgraciadamente no se ha encontrado restos físicos de estos instrumentos que permitan un estudio organológico (número de tubos, material de construcción, dimensiones, sonoridad, etc.), es posible que las "antaras reales" fueran construidas en material orgánico (cañas) por lo que el tiempo y el clima no habrían permitido su conservación. En la actualidad, en las zonas donde ha sobrevivido este modelo de "antaras", se construyen en este material perecible puesto que se trata de zonas amazónicas, como es el caso de las etnias Maku y Kuna. ${ }^{11}$

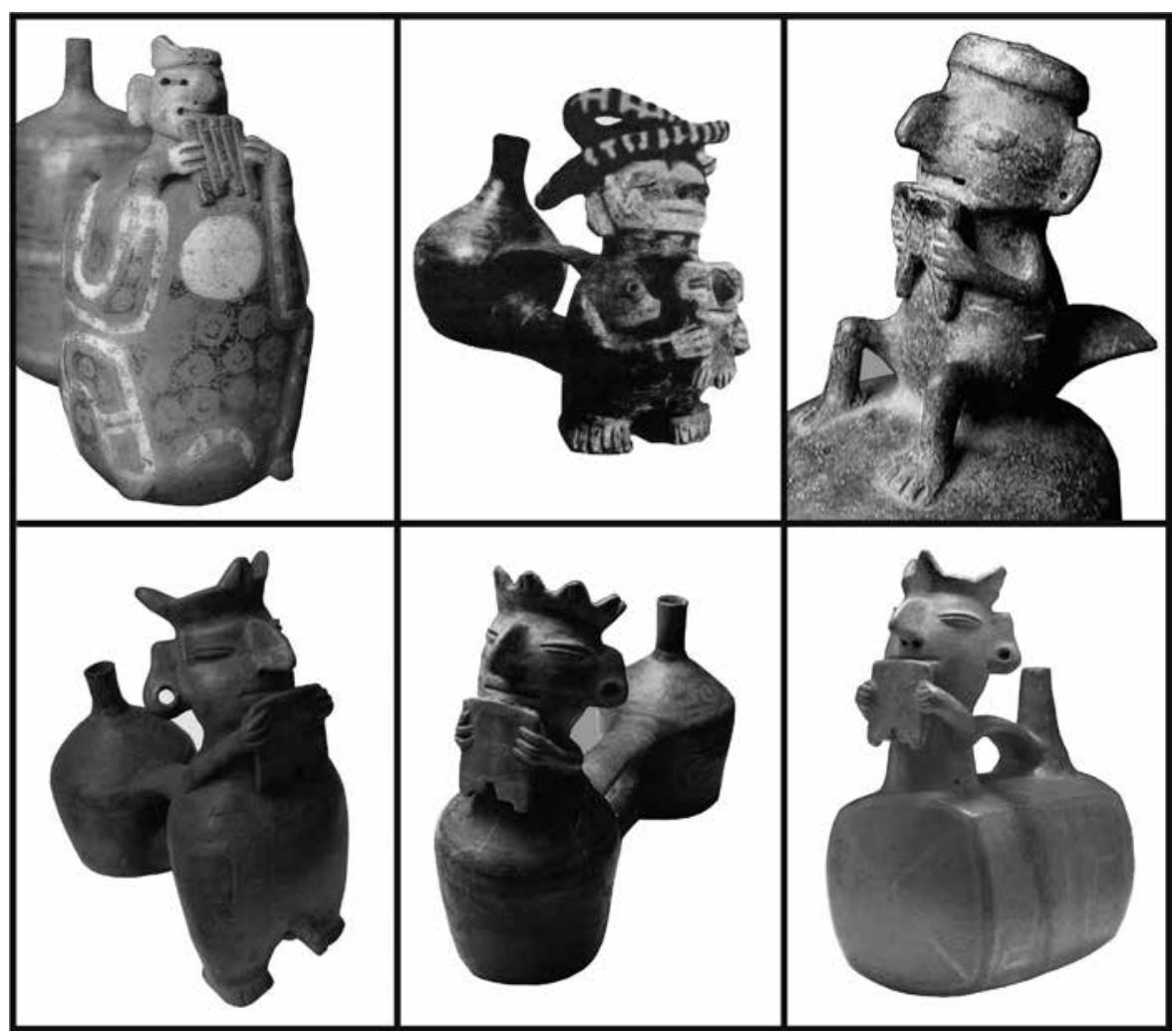

Fig.10) Vasijas escultóricas Vicús, en su totalidad demuestran el uso de una "antara" diferente, el modelo "W". Instrumentos musicales de "tamaño regular" sujetada siempre con ambas manos (imágenes tomadas de Sánchez 2013).

11. La etnia Kuna (o Cuna) es un pueblo originario que ocupa gran parte de la selva de Colombia y Panamá. Su idioma la hace parte de la familia lingüística chibcha. En lengua kuna se autodenominan dule (o tule), que significa "persona". Esta etnia posee una flauta de Pan muy particular, cuyo modelo hemo señalado que pertenece al área cultural norteña (modelo "W" de Ecuador y parte del norte peruano), en cuyos lugares no ha sobrevivido. Esta flauta de Pan kuna se denomina kammu burwi, purwi o purruy, se fabrica con "cañas" de la zona, colocadas en una sola fila partiendo de tubos grandes y gruesos en los extremos, hacia el centro disminuyen a las notas agudas dejando un vacío simple al centro, un lado posee cuatro y el otro tres tubos, haciendo una flauta de siete notas. Existen dos tipos diferentes de flautas, las que son conocidas como hembra (más grande) y macho (menor), estas son tañidas de tal manera que en ciertos momentos se nota claramente un tipo de diálogo musical (Sánchez, 2013, p. 76) 
Estas diversas representaciones nos permiten imaginar que la "música de antaras" habría estado fundamentalmente a cargo de una élite y para una élite, y/o se trataría de músicos y música sagrada y para momentos muy especiales (coronaciones, sanaciones, pasajes o traslaciones como la muerte, etc.). Ciertamente algunos de estos personajes portan "monteras" en la cabeza y otros aditamentos (orejeras, pinturas, etc.) algunos más solemnes que otros (fig. 10b) que nos hacen suponer roles y funciones especiales. Este tipo de presupuestos serán siempre arriesgados, pues normalmente las cerámicas de este tipo también fueron construidas como ofrendas especiales o de la élite, mientras que poco nos dicen de los sectores populares.

En sociedades pre hispánicas de lo que hoy es Ecuador (de los 500 a.C.) como La Tolita, Bahía; Guangala y Jama Coaque (fig. 11), encontramos el uso de este modelo de flautas de pan e inclusive podemos distinguir "variedades" del modelo "W" (Sánchez 2013). En todo caso nos queda claro que este modelo pertenece a toda esta área cultural norteña y evidencia un amplio desarrollo y profuso uso hasta los inicios de nuestra Era. Además, de acuerdo a los vestigios arqueológicos convive plenamente con otros dos modelos de "antaras" norteñas más conocidos: el clásico "modelo triangular de tubos escalerados" y el "modelo intercalado o alternado"; el primero supervive bajo la denominación común de "antara" (fig. 11a) y el segundo es muy conocido en el Ecuador como "rondador" (fig. 11c).

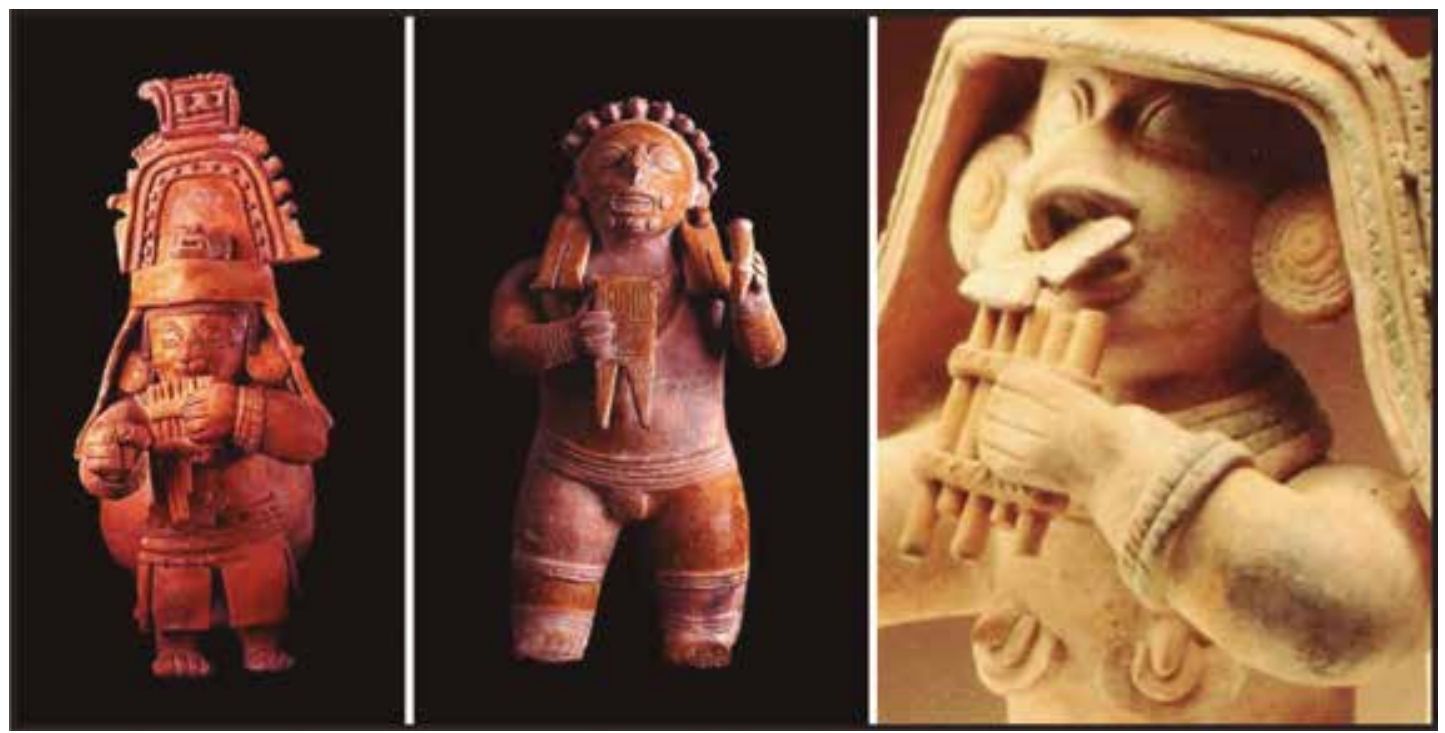

Fig. 11) Las sociedades prehispánicas norteñas (Ecuador) evidencian un profuso conocimiento de las flautas de pan de los tres modelos más conocidos: 11a) Triangular (modelo de "antara" clásico, en escalera simple). 11b) Modelo "W" (en escalera convergente). 11c) Modelo "escalerado" o de tubos alternados, llamado comúnmente "rondador" (Imágenes tomado de Sánchez 2013).

\section{ViRÚ o Gallinazo (100 A.C. - 300D .C.)}

Esta cultura descubierta en el valle de Virú, departamento de La Libertad, precede y luego "convive" con la cultura Mochica (o tal vez fue expulsada o absorbida por esta) (Hocquenghem 1987, Makowski 2010), presenta también un uso furtivo de "antaras" que se ven reflejado en muchas cerámicas escultóricas. Tampoco se han encontrado restos materiales de flautas de Pan. El Dr. Rafael Larco fue el más asiduo investigador de esta sociedad y muestra de ello es que la mayoría de vasijas con "antaristas" se encuentran en el museo Larco (ML) de Lima. 


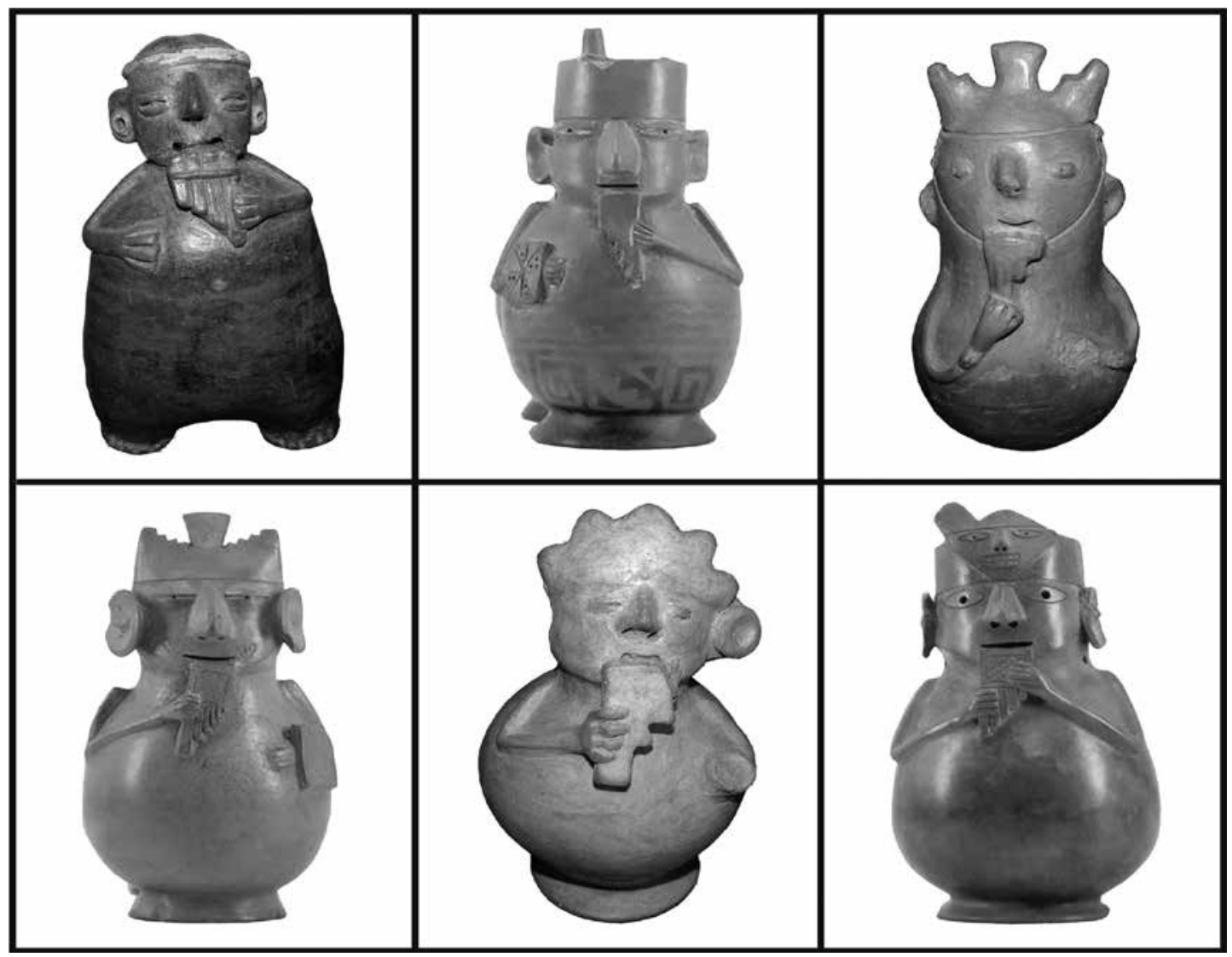

Fig. 12) Estas botellas de asa-puente de la sociedad Virú evidencia el amplio conocimiento de flautas de pan de modelo "clásico triangular" y observamos un posible "uso militar" en algunos casos. (Imágenes del Museo Larco, Lima).

Las sociedades costeñas al sur de Piura empiezan a contarnos su historia musical con mayor énfasis en el periodo del Intermedio Tardío, con influencias que vienen más del sur que del norte, ello explica el uso de modelos de flautas de pan que vienen de Paracas ("antaras" bulbosiformes) y no de Vicús ("antaras" modelo "W"). En este caso en un periodo pre-Mochica podemos observar el uso del modelo "clásico triangular escalonado" y al igual que en Vicus, Salinar y en el mismo Mochica, no se han hallado restos físicos, artefactos sonoros del tipo "antara" que nos puedan dar mejores pistas sobre estos. Sin embargo, la presencia de estos instrumentos en esferas sociales de importancia han sido muy bien grabadas en las cerámicas (fig. 12).

En estas vasijas observamos la preeminencia de "personajes militares", ellos poseen escudos, vinchas, "monteras" y tatuajes que indican altas jefaturas o personajes (individuos solistas) especialmente dedicados a la música en el momento de los combates o ritualidades de enfrentamientos (tinkus por ejemplo). Observemos que sus "antaras" son de "tamaño regular" con una cantidad de tubos que oscila entre 4 y 6, y dependiendo del personaje parecen estar bien presentables ("adornadas"). En todos los casos sujetan el instrumento con una sola mano de manera indistinta (izquierda o derecha) y ordenan las "antaras" con los tubos mayores o grandes hacia el lado derecho. Al parecer a esta cultura le significó mucho el uso de estas flautas de pan en el contexto de los combates, muy probablemente 
rituales (o talvez guerras). Finalmente, al igual que en el caso anterior tampoco se han encontrado restos físicos por lo que podemos deducir que estos no fueron construidos en cerámicas a diferencia de la zona sur donde había florecido la sociedad Paracas y venían emergiendo los nazcas usando con mucha dedicación la cerámica para la construcción de sus flautas de Pan.

\section{Mochica o Moche (200 A.C. - 800 D.C.)}

Se trata de una de las sociedades precolombinas más representativas del periodo pre hispánico que se extendió a lo largo de la costa norte del Perú. Su centro cultural fue el territorio comprendido entre el valle Moche, valle de Chicama y valle de Virú, pero ocuparon los valles de Piura, la Leche, Lambayeque, Zaña, Jequetepeque, Moche, Chao, Santa y Nepeña. Desde allí se expandió cubriendo desértica franja costera entre el valle de Piura -como límite Norte- y el valle de Nepeña -como límite Sur-. Fue un pueblo de grandes maestros artesanos que trabajaron la cerámica retratando la vida cotidiana y sus creencias religiosas con tal refinamiento que asombran hoy a nuestras sociedades contemporáneas. Entre los artefactos sonoros e instrumentos musicales que sabemos que utilizaron tenemos: aerófonos ("antaras", "quenas", silbatos, pututos, vasijas silbadoras y trompetas), membranófonos (bombos y/o tambores) e idiófonos (campanillas y sonajas). El momento de sus usos y sus "lenguajes" musicales, es el aspecto más incierto y sugestivo del mundo de los Mochicas, debido a la gran cantidad de iconografías complejas.

Las flautas de pan de los mochicas.- La gran cantidad de iconografía y ceramios nos demuestra el conocimiento, uso e importancia de las "antaras" de modelo "clásico triangular" para esta sociedad. Sin embargo, una representación especial se empieza a notar en algunos de estos: antaristas en dúos (como en la actualidad se interpretan los sikus ${ }^{12}$ ), el mismo que revisaremos en el presente. Pero a pesar de esta cuantiosa evidencia, muy pocas "antaras" se han encontrado, por lo que algunos estudiosos suponen que debieron haber sido construidas de material orgánico (caña) y que el tiempo y la geografía destruyeron (Bolaños 2007, Valencia 1989). Sabemos solo de tres "antaras" construidas de cerámica (fig. 13). A continuación revisaremos los caracteres más resaltantes de las flautas de pan Mochicas.

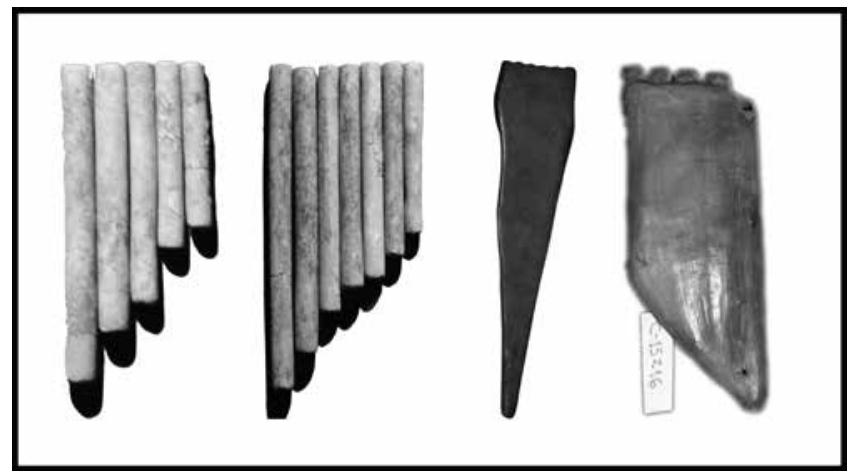

Fig. 13) Restos de flautas de pan Mochicas: a) "Antara" de cerámica con caracteres "bulbosiforme" (Museo Casinelli de Trujillo, Perú), b) "Antaras" halladas en la tumba del Sacerdote Guerrero de Sipán (Museo de sitio de Huaca Rajada) y c) "Antara” de cerámica de cinco tubos (MNAAHP).

12. En la actualidad una variedad de flautas de pan andinas, llamadas sikus (antiguamente ayarachi, phuko, phukuna, etc.) del altiplano peruano boliviano son tañidos bajo la técnica del "hoquetus" o del sistema "pareado" constituyendo una flauta de pan dividida en dos al cual se denominaremos "dual complementaria" o "dual interdependiente" (Autores). 
Las flautas de pan en la "otra vida".- La relación entre la muerte y las flautas de pan aparece de manera muy acentuada en la sociedad Mochica constituyendo un complejo simbólico aún no descifrado. La muerte (la "otra vida") es un tema muy recurrente en la cerámica e iconografía Moche, se trata de un "mundo" -a decir de Jurgen Golte- frío, que se encuentra ubicado "abajo", en el subterráneo, en el inframundo, en el Uku Pacha o el mundo de ultratumba, se trataría de un "lado" femenino, húmedo relacionado con la noche y el mar. Es considerado la siguiente etapa de la vida, es simplemente "la otra vida" por lo que prácticamente se piensa que lo caracteriza el mismo patrón cultural de "este mundo", donde se puede incluir la música, posiblemente se trate también de un mundo silencioso, perfecto para la sonoridad. Sin embargo, la recurrente presencia iconográfica de "parejas de antaristas" en este inframundo, nos exige una mayor reflexión sobre el papel y la simbología de este dualismo puesto que creemos que trasciende la representación simple de la dualidad: vida y muerte o arriba y abajo.

Las escenas parecieran connotar en muchos casos estados liminales entre momentos opuestos: vida y muerte principalmente. En la mayoría de casos aparecen "antaristas cadavéricos", los mismos que fueron señalados por Américo Valencia como "despellejados" y a quienes supuso que pudieron haber tocado las "antaras" aún en vida en un estado que mesclaría el dolor del padecimiento rumbo a una muerte segura con la música. Nosotros nos acercamos más a la idea de una representación simbólica de la importancia y el rol de la música en ese nuevo espacio de vida que aunque suena paradójico ("vivir en la muerte"), es la muerte y el otro mundo al cual asistían cual si fuera la continuidad común de esta vida. La muerte es una realidad y de seguro el espacio más cercano a sus dioses, un espacio y momento divino para lo cual se destinaba una especial "música" (o sonoridad) y los instrumentos que la producían.

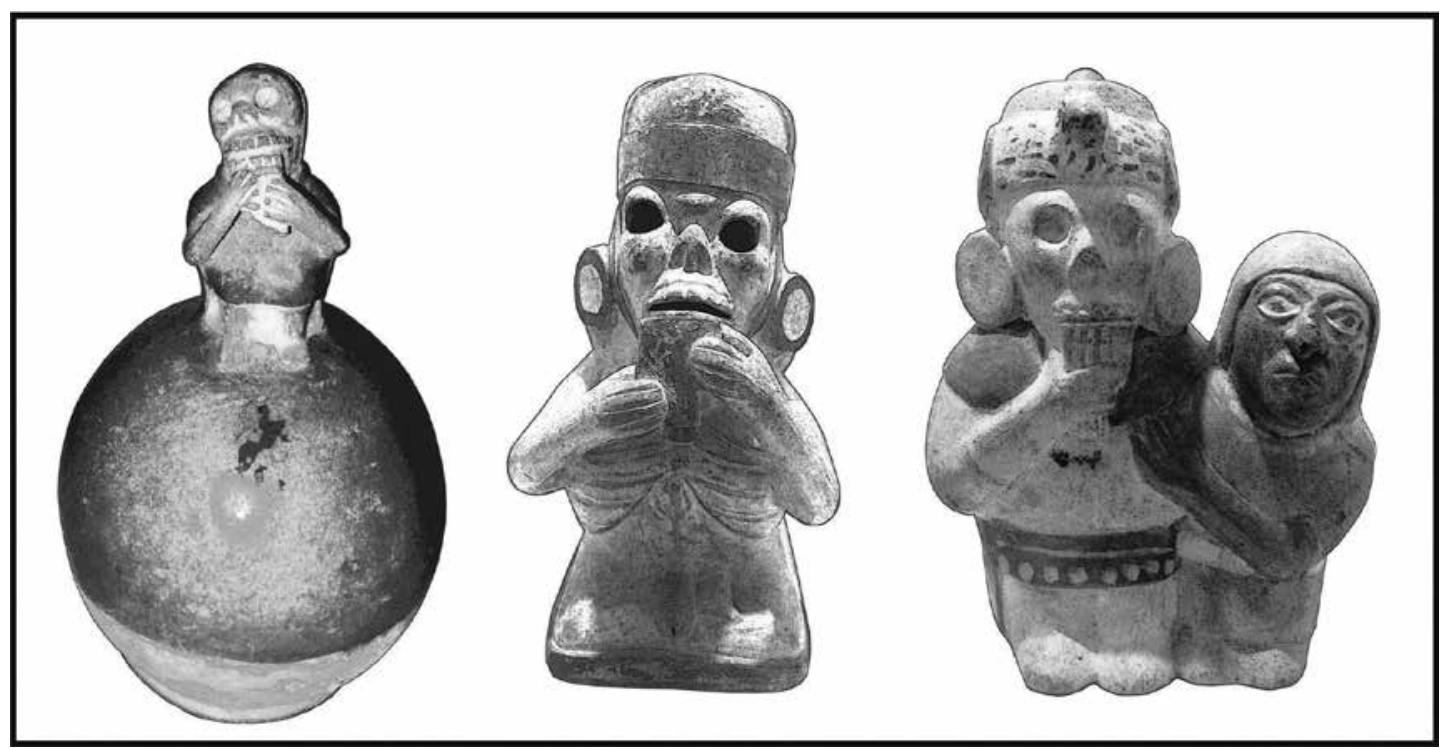

Fig. 14) Música de antaras y muerte: 14a) Botella escultórica con personaje de capa esqueletizado (Museo de la UNMSM). 14b) Botella gollete de asa estribo representando hombre muerto tocando "antara", viste turbante con diseños y orejeras (ML004328). 14c) Botella escultórica representando a mujer y hombre muertos y abrazándose y él toca la "antara" (ML004336) 
Rafael Larco sugería que el hecho de que los esqueletos "viven" para encaminarse jubilosos hacia el más allá, comprueba que los antiguos mochicas no creían que todo acababa con la muerte del cuerpo, muy por el contrario "se iniciaba una nueva vida". Es por ello que se pueden ver individuos esqueletizados haciendo una vida sexual que no difiere de la de los vivos, talvez entre lujuria y reproducción se extendía en la vida en el Uku Pacha: "En algunos ceramios del museo observamos a personajes que dan la impresión de que están bebidos y que son los asistentes a una fiesta en su vida de ultratumba, Se realiza un gran baile de esqueletos, entre los cuales abundan recipientes conteniendo bebidas y alimentos. En la danza macabra los esqueletos se muestran con los miembros en erección, bailando cogidos de las extremidades superiores." (Larco Hoyle 1965, p. 90)

Sexo y flautas de pan.- Está demostrado que el sexo formaba parte de los ritos funerarios (Hocquenghem 1987, Bourget 2007), el sexo anal y la masturbación parecen ser los más representativos cuando las escenas de sexo y muerte se relacionan con las "antaras". Los actos sexuales se pueden (o tienen) que comprender dentro del proceso de ritualidad en un evento funerario y/o como parte del duelo. Hocquenghem se inclina a creer que las escenas sexuales "al revés" (inversión) como masturbaciones, felaciones y sodomías están asociadas a pasajes de entradas a otro mundo y se encuentran dentro del esquema dualista cosmogónico de las épocas húmedas frente a lo cálido, y el mundo de los muertos inverso al de los vivos. Es posible que las "antaras duales" en el mundo del Uku Pacha, reflejen esta bi-partición, así mismo las iconografías mochicas nos demuestran que el sexo y la música de "antaras" se relacionan sólo en el mundo de los muertos.

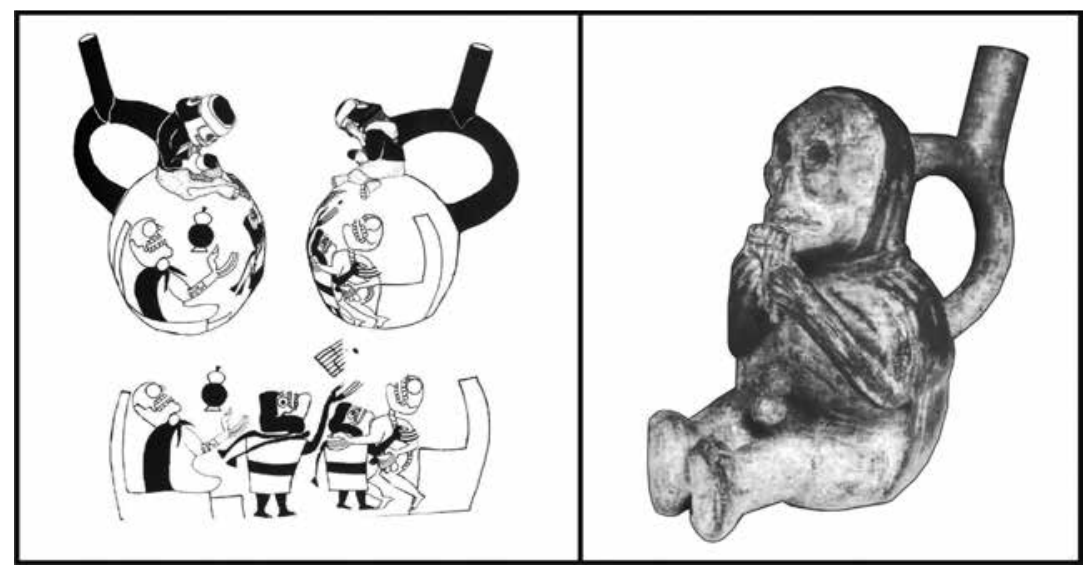

Fig. 15a) "Muertos y mujeres con uta tratando de recibir semen de un masturbador que sufre del mismo mal, antara y semen entre los actuantes" (Tomado de Golte 2009). 15b) Un ser cadavérico "toca" la "antara" mostrando su pene erecto, que parece ser lo "único" vivo. (ML004326)

En la iconografía de la figura 15a observamos a un hombre cadavérico realizando un acto de masturbación mirando hacia el Uku Pacha, se encuentran dos mujeres al parecer en proceso de muerte (aún visten "anacos" y tienen cabellera pero con rostro cadavérico) y dos varones cadavéricos, uno de ellos aún viste una capa de distinción, los que según Jurguen Golte "están estrechando las palmas de sus manos para recibir el semen (...) resulta explícita esta escena en cuanto a las carencias del mundo de los muertos y la posibilidad de suplirlas por actos de transferencia del semen del mundo de los vivos al de los muertos" (p. 65). La "antara" aparecería mediando entre estos dos espacios actuantes, indicando muy posiblemente la presencia o necesidad de la música en la comunicación dentro del mundo de los muertos, entre un nivel y otro. 


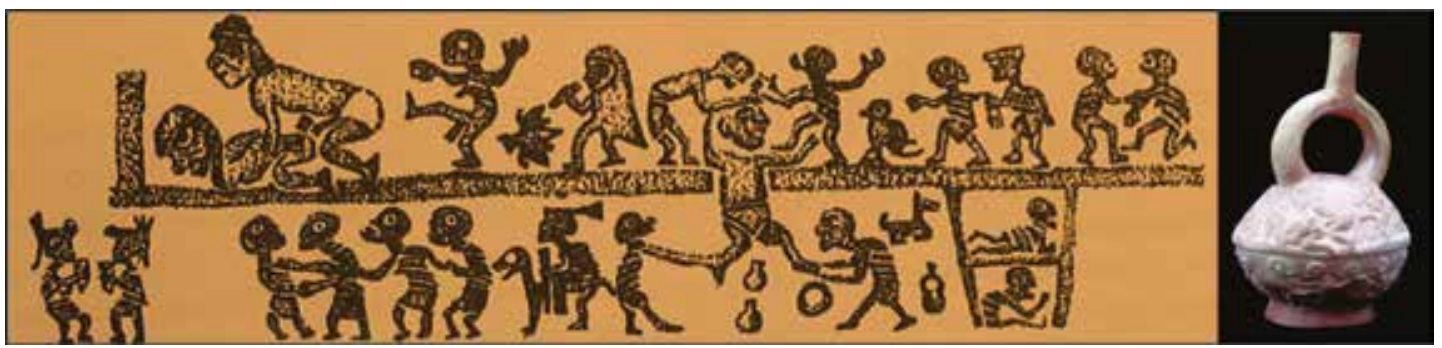

Fig. 16) Una escena que pareciera tener dos espacios en el mundo de ultratumba y en lo más profundo, la música de las "antaras duales" ejecutados por dos músicos cadavéricos nos lanzan algún mensaje mayor, aún oculto

(Tomado de Hocquenghem 1989).

Hocquenghem (1989) nos dice sobre la iconografía de la figura 16: "Dos muertos se ocupan de jalar el cuerpo hacia abajo, otros dos yacen en lo que parecen ser tumbas, un grupo de muertos baila al son de las flautas. Un acto de sodomía entre un hombre y una mujer y un acto de masturbación entre muertos se asocian con ciertas actividades de éstos, reconocibles por sus aspectos de esqueletos. Esta escena se desarrolla en dos niveles. Al nivel superior tiene lugar los actos sexuales mientras que los muertos tiran sobre los vivos objetos redondos, que parecen ser piedras, tocan flautas y, detalle que aquí nos interesa, tratan de empujar en el nivel inferior a un ser que conserva su cuerpo. El ajuar funerario ya se encuentra en el nivel inferior. Están presentes dos animales nocturnos, un murciélago y un búho. Al nivel inferior cerca del material funerario se nota un perro y una llama, animales que hasta hoy en día se dice que siguen al muerto en su viaje en el otro mundo, para ayudarlo a cargar sus bienes." (p. 141)

Sobre estos "ritos fúnebres o de duelo", la autora realiza una interpretación utilizando datos etnohistóricos y etnológicos recogidos en actuales tiempos en diversas zonas andinas. Estos dan cuenta de algunas "inversiones" en el comportamiento de la gente en momentos de duelo (contrarias a las costumbres y a la moral cristiana), como por ejemplo las mujeres se cortan el cabello, los hilos se tuercen hacia la izquierda, hay abstinencia de la sal y el ají, se ven ofensas a las personas mayores y principalmente se realizan actos sexuales inversos (los que no generan fertilidad como la masturbación y la sodomía, como en las iconografías). De tal manera que todo indicaría que "el mundo de los muertos es siempre concebido como inverso al de los vivos" (Hocquenghem 1989:141).

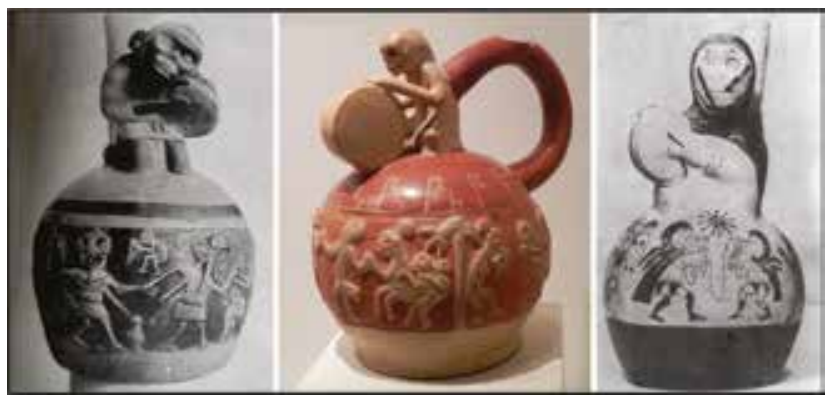

Fig. 17a) Preeminencia de la percusión ("bombo" o "tinya"), abajo se forman círculos "festivos de muertos" donde las "antaras duales" son los instrumentos fundamentales en los tres casos (Tomado de Tello 1938). 17b) Museo Larco 002872. 17c) Círculo de fiesta al compás de la percusión y el "dúo de antaristas" ahora mejor ataviados pero que probablemente se encuentre también en el "mundo de los ancestros".

Antropomorfismo y flautas de pan.- Hay también en las iconografías y cerámicas de la cultura Mochica una fuerte presencia de seres antropomorfos antaristas; esta antropomorfización se da con los primates ("monos") y en el caso de San José de Moro con las iguanas. No hemos observado otros animales. En el caso de los "monos" estos aparecen cadavéricos, mientras que en el caso de las iguanas parecen simbolizar poder y prestigio en la vida terrenal (fig. 18). 
Sobre el significado o simbolismo de los primates en las iconografías, no encontramos un consenso, Fernández Alvarado (2014) sostiene que se trata de un animal relacionado con las deidades y rituales propios de la fertilidad. Steve Bourget (2007) lo señala como el símbolo de la muerte (hombre = vida y mono = muerte): "La interacción entre la vida y la muerte es a menudo representada con la ambigüedad entre mono y personaje esqueletizado o calavera (...) así, ocurre una doble dualidad entre la vida y la muerte y entre un ser humano y un mono. En otra vasija retrato, el doble juego entre lo humano y animal y entre la vida y la muerte se expresa en la cara, mostrando a la vez rasgos humanos, de mono y de esqueleto" (p. 8)

Es importante tener en cuenta que existe en el universo Mochica animales antropomorfizados (zorros, felinos, venados, murciélagos, iguanas, lechuzas, patos, etc.) mientras que otros animales como el perro, el cuy y la llama que nunca lo fueron, pero para Bourget (2007), el "mono" pertenecería a un tercer tipo de sujetos y al parecer tendrían atributos justamente de conexión con el mundo del "más allá": "sujetos que he denominado "transitorios": la cara mutilada (o muerto-viviente), el esqueleto-mono, el tuerto y los personajes esqueletizados. Ellos realizan un sinnúmero de actividades como cuidar un ataúd, acarrear ofrendas funerarias, tocar música y bailar (...) he involucrados en actividades sexuales (...) Los seres transitorios parecen tener una asociación especial con escenas y actividades relativas a rituales funerarios y en menor grado con sacrificios." (p. 9) "Como hipótesis se puede sugerir que en la iconografía Moche existe una etapa transitoria entre la vida y la muerte que parece haber sido expresada por medio de un número de elementos simbólicos -seres duales o seres transitorios- tales como los muertos-vivientes, el hombre-mono y el tuerto." (p. 9) A los cuales podríamos incrementar nosotros: la dualidad de los músicos que tocan dos antaras en vez de una.

Si es que los monos representan temas de fertilidad y estas se hallan ligados a conceptos de muerte y la vida en el más allá, entonces es posible como supone Alvarado que el "mono" es la figura o símbolo de la fertilidad lo que nos llevaría a deducir que la música ligada a ella forma parte también de la fertilidad y esta dualidad de instrumentos representaría a la vida y a la muerte.

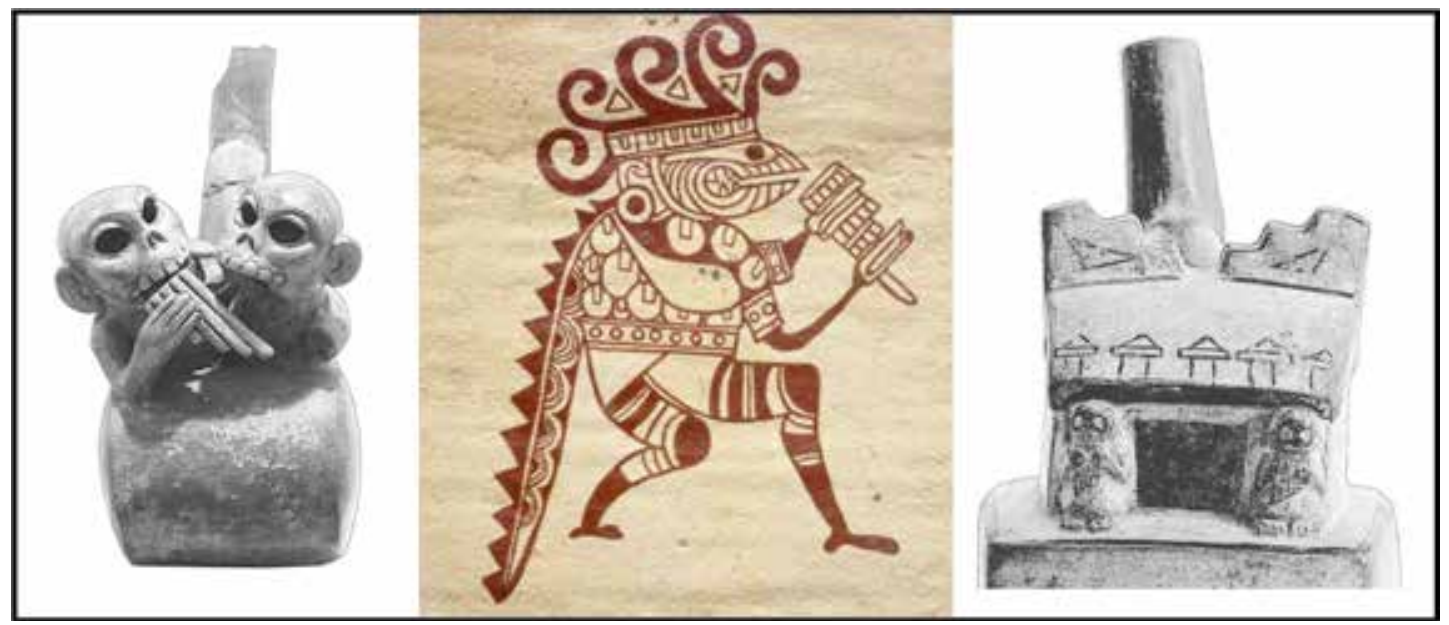

Fig. 18a) Botella escultórica representando dos "hombres monos muertos" en posición de cúbito ventral, uno de ellos toca la antara (ML004325). 18b) Iconografía donde dos "hombres iguanas" tocan las antaras frente a frente (hemos obviado a la segunda iguana para esta figura), por sus aspectos simbolizan poder, prestigio y posiblemente divinidad (Tomado de MacClelland y Donnan 2007). 18c) Botella escultórica que representa sin duda una "casa real" pues está resguardado por dos "monos" que tocan sus antaras (ML002899). 
Poder y prestigio.- Las evidencias nos llevan a suponer que las flautas de pan eran usados principalmente por la nobleza (político, militar y religioso) Mochica, se trata al parecer de una música e instrumentos sagrados y de la élite: 1) Muchos "antaristas" se encuentran presente en sucesos mortuorios del señorío Mochica, junto a personajes importantes (fig. 18 b y c). 2) La presencia de estos músicos las encontramos grabados en cerámica fina, ofrendados sin duda en los funerales de los grandes personajes, de los cuales justamente representa sus escenas de entierros y pasaje a la siguiente vida (la muerte). 3) No se han hallado cerámicas de este tipo en entierros de pobladores comunes. 4) Observamos muchas representaciones de "antaristas" muy bien ataviados, lo que significa una muy buena posición del personaje, esto nos lleva a reafirmar que la música de las "antaras" habría sido también selecta (fig. 19). 4) Con el descubrimiento de una de las pocas flautas de pan en la tumba 14 del "sacerdote guerrero", uno de los personajes principales de la famosa iconografía de la "presentación" o "sacrificio" queda demostrado la predilección de este instrumento musical. ${ }^{13}$

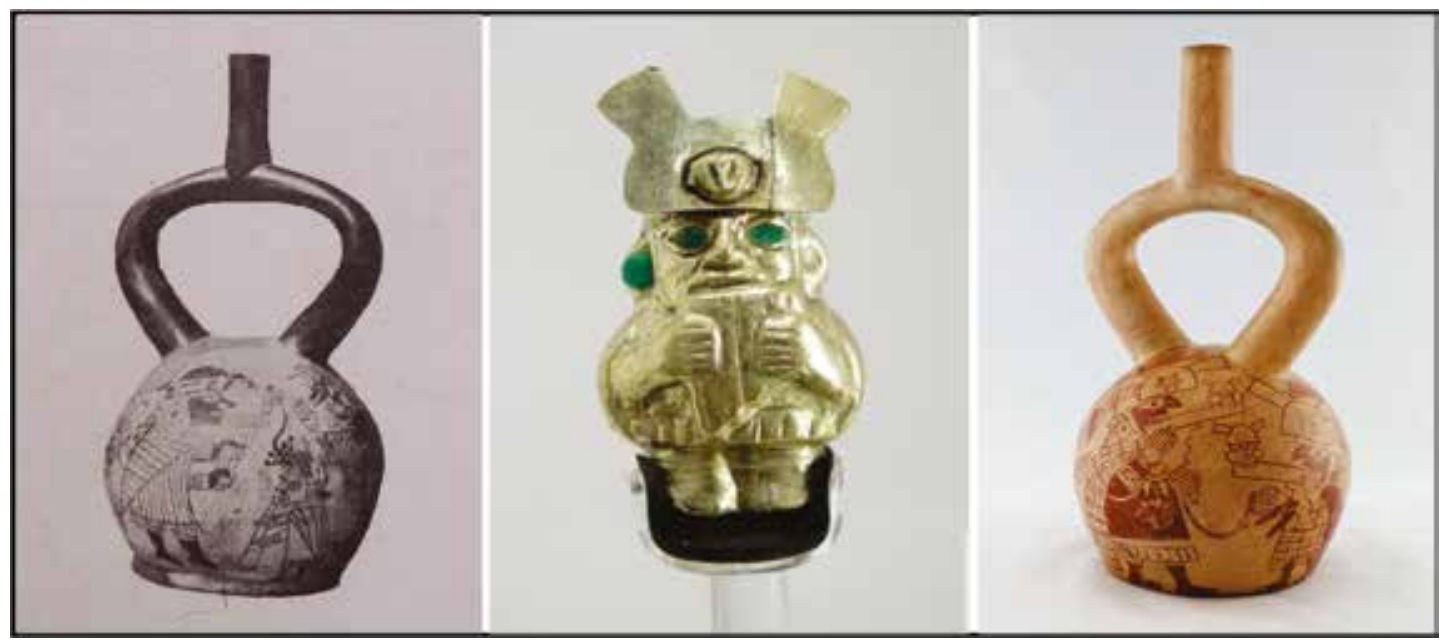

Fig. 19 a) Vasija cuya iconografía presenta a personajes muy bien ataviados tocando flautas de pan (tomado de Tello 1938). 19b) Figura de oro que forma parte de una Vara de mando, representa a un personaje importante tocando una "antara" (Museo Larco). 19c) Vasija cuya iconografía vuelve a presentarnos a personajes muy bien ataviados tocando antaras también muy bien decoradas (tomado de MacClelland y Donnan 2007).

La flautas de pan duales de los Mochicas.- El dualismo andino, construido desde los primeros asientos sociales, de hecho debe trascender los ritos mortuorios, para Bourget (2007) en el caso Mochica abarca "todo el ritual, incluyendo edificios, murales y los sitios de entierro y de sacrificio. En los murales, la dualidad simbólica es expresada en la diferencia entre las representaciones de las murallas de la Huaca. Las exteriores, que podían ser vistas por el ciudadano común, estaban cubiertas con rituales de guerra y figuras de animales de las montañas o mayormente del mundo terrenal.” (p. 5)

Las flautas de pan andinas, desde algún momento de su desarrollo, se "bi-particionan" y se hacen dos "sub instrumentos" los que obviamente juntos recién logran conformar la unidad, allende se requiere dos músicos en vez de uno. A esta peculiar característica le denominamos "flautas de pan duales complementarias o interdependientes" el mismo que en la actualidad lo podemos observar en los conjuntos de sikuris del altiplano peruano / boliviano y a cuya flauta de pan dual complementaria

13. Ver: "La flauta de pan del sacerdote guerrero de Sipan en (de) la alta jerarquía Mochica (avances de investigación) en la Revista del Museo de Arqueología de la UNMSM Nº 30. 
se le denomina siku. En el caso mochica observamos en muchas iconografías a dos personajes tañendo flautas de Pan "frente a frente" o "lado a lado" incluyendo en algunos casos lazos que unen estos dos instrumentos y en algunos casos considerando un "bombo" en el centro (instrumento de percusión muy parecido con las actuales "tinyas" de las serranías andinas). Estas representaciones han hecho suponer al investigador Américo Valencia que la sociedad Mochica habría dado inicio al "siku bipolar" (flauta de pan dual complementario), teoría refutada por otros estudiosos como César Bolaños quienes suponen que al parecer se tratarían de flautas de pan "duales", pero no necesariamente "complementarias o interdependientes" en la medida que estas muestras no certifican esto último.

En lo que están de acuerdo los investigadores especializados en el mundo Mochica es que esta dualidad simboliza la bipartición de la cosmogonía andina, la existencia y relación entre dos mundos, estaciones y/o fuerzas. Mientras que el instrumento de percusión que algunas veces aparece en el centro de esta dualidad musical, representaría el momento propiciatorio. La dualidad o la pareja de antaristas aparecen en escenas de muerte y entre personajes distinguidos (líderes políticos, militares y religiosos a la vez), la música de "antaras tocado entre dos" está muy presente (fig. 7 y 20).

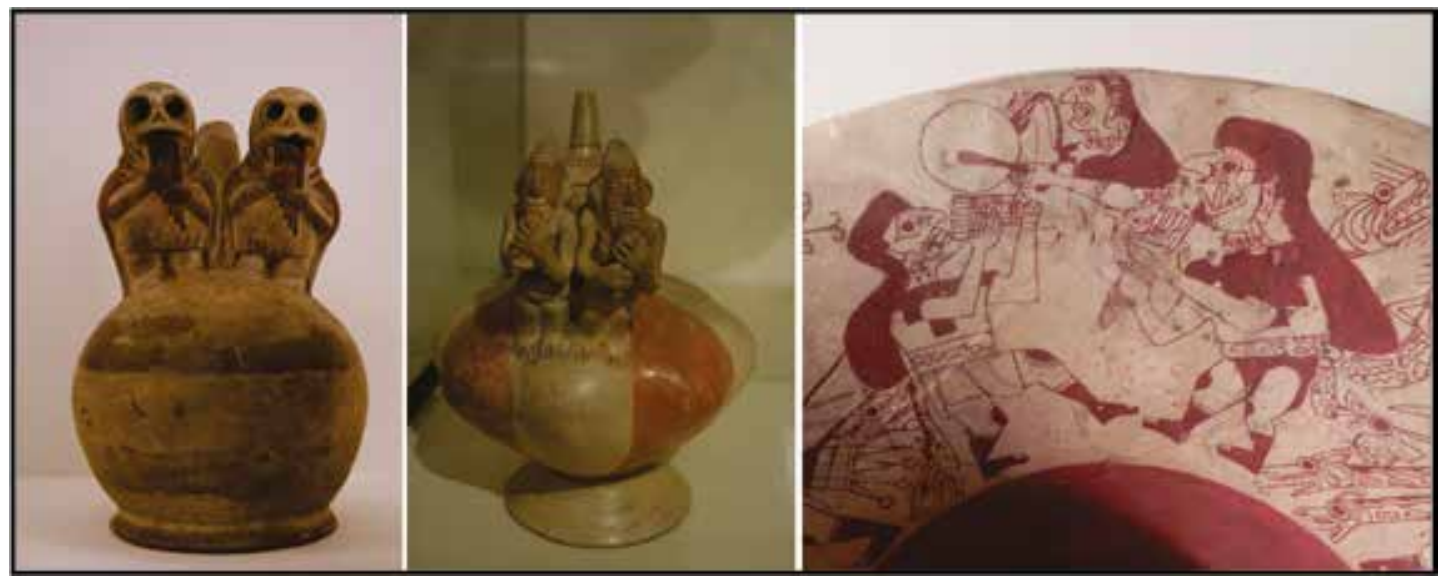

Fig. 20) Muestras evidentes de dualismo con las "antaras" en los Mochicas: 21a) Vasija que sostiene a un dúo cadavérico en posición de tocar antaras (Museo de Berlin). 21b) Vasija que sostiene a dos tocadores de "antaras" los que evidentemente se encuentran "vivos" (Museo Casinelli). 21c) Vaso acampanulado pictórico con representación de escena mítica: dos personajes antropomorfos (con colmillos de felino) tocando "antaras" entre ellos otro personaje antropomorfo tocando "bombo" (ML018882).

\section{Nazca (200 A.C. - 600 D.C.)}

Hacia el sur de la costa peruana, el gran desarrollo de las flautas de Pan logrado por la cultura Paracas es continuado por la sociedad $\mathrm{Nazca}^{14}$ mejorando o logrando una excelente técnica en el uso de la cerámica para su construcción; todo esto evidencia los grandes alcances en la producción musical: constructores, músicos, público consumidor de la misma, momentos de presentación (fiestas,

14. Los estudios sobre las "antaras" Nazca es más o menos abundante y dan fe del alcance superior y complejo al que llegaron: Charles Mead (1924), Raoul y Marguerite d'Harcourth (1925), Carlos Vega (1932), Mariano Béjar Pacheco (1935), André Sas Orchassal (1938-1939), Robert Stevenson (1959), Alberto Rossel Castro (1960), César Bolaños (1980-1988), Américo Valencia Chacón (1982), Miguel Oblitas Bustamante (1984-2009), Arturo Ruiz del Pozo (1992), Giuseppe Orefici (1999), Anna Gruczinska (1999; 2009), Milano Trejo y Carlos Mansilla (2006) y otros. 
sanaciones, traslaciones, etc.), cada uno de seguro muy especializado. La cantidad y excelencia con que fueron construidas sus "antaras" implica además un diferenciado concepto de la música frente a la sociedad Mochica, donde por ejemplo casi no hay restos físicos de estos instrumentos y sus representaciones iconográficas demuestran una inextricable concepción de estas. En cambio, la sociedad Nazca ha "entregado" casi un ejemplar por museo en el Mundo y cientos de ellos aún "duermen" en los almacenes de nuestros museos. Entonces una gran interrogante emerge: ¿Por qué la sociedad Mochica y la Nazca se diferencian extremadamente en este tema? Precisemos además que lo mismo sucede con los membranófonos, entre los Mochicas usaron el bombo tipo "tinya" no sobrevivió mientras que los nazcas continuaron el modelo Paracas de cintura con base cerrada y con una sola membrana, los silbato "bífonos" son abundantes entre estos últimos mientras que entre los Mochicas estos modelos no existen.

La sociedad Nazca desarrolló un uso calificado, diversificado y masivo de las llamadas (o mal llamadas) "antaras": "Se produce en Nazca un gran auge de la antara inserto en un desarrollo de todas las artes" (Pérez de Arce 1993: 475). Sin duda fue muy importante este instrumento musical para esta sociedad pues encontramos una gama de diversidad morfológica y musicológica: 1) En el Período Nazca Temprano se observa la influencia Paracas con la existencia de las "antaras de modelo Paracas" (de "tubos complejos" descritos al inicio del presente). 2) Posteriormente y en adelante tiende a desaparecer este "modelo de tubos complejos" y se busca una uniformidad casi absoluta de los tubos. 3) En este contexto aparecen las embocaduras ojivales (anillos) al borde inicial de los tubos, el mismo que por efectos de la acústica produce una sonoridad muy especial: fina y dulce, menos "exaltada", con menos armónicos o sonidos de batimento que producían los modelos Paracas (de tubos complejos). 4) Los talleres de construcción debieron ser muy especializados pues se distingue un conocimiento excepcional a lo largo del proceso de fabricación que es largo y complejo: recoger y preparar la arcilla, modelar, secar, afinar, quemar, etc. Las "afinaciones" de las "antaras" que forman parte de una orquesta reafirman este conocimiento: "Opino que los resultados de los análisis (con un grupo de antaras Nazca) ofrecen bases bastante firmes para rechazar de plano cualquier insinuación sobre una afinación imprecisa de las antaras, torpe, caótica o consecuencia de una construcción poco esmerada de los instrumentos." (Gruszczyñska 2009: 164). 5) Las evidencias arqueológicas demuestran que conocieron las formas de ejecución individual de las "antaras", pero también pudieron haber conocido otras dos formas musicales propios del mundo andino actual: las antaras duales o en parejas (posiblemente "antaras complementarias a la octava", según Bolaños) y el sistema musical de orquestación o colectivización de la música. 6) Se observa la existencia de flautas de Pan para distintos momentos de la vida en sociedad, pues morfológicamente existen las "antaras" más diversas e imaginables, parecieron haber cumplido roles desde "adornos", hasta juguetes y ofrendas. 7) También parecen haber sido forma de sobrevivencia de músicos solitarios y discapacitados, muy posiblemente los más indicados para realizar música de antaras, En la figura 21 observamos un "tipo" de estos personajes. ${ }^{15}$ 8) Las evidencias señalan que hacia los finales de la sociedad Nazca, posiblemente con la influencia Wari se inicia el retorno a las "antaras" construidas en cañas o carrizo (Orefici y Drusini 2003), olvidándose poco a poco de las brillantes técnicas en cerámica.

15. César Bolaños (2007a: 111) señala: “Otra escena muy peculiar es la de un ejecutante que, teniendo los pies, las manos y el sexo amputados, demuestra destreza al tocar simultáneamente una antara, una sonaja y un tambor (Fig. 143)". 


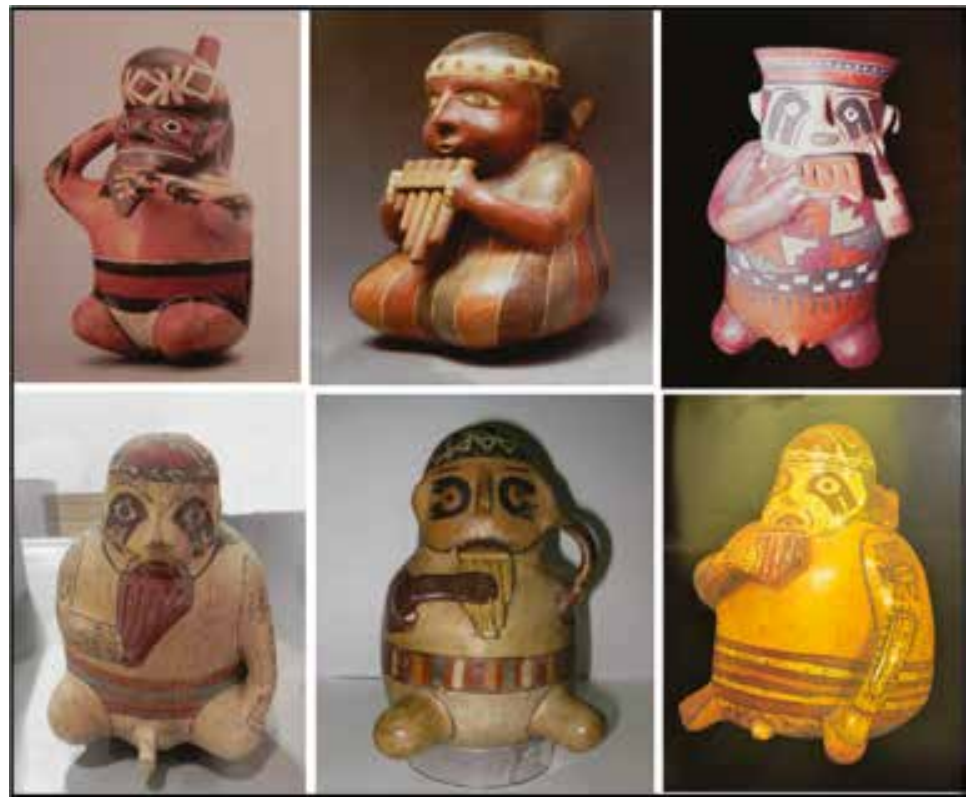

Fig. 21) Personaje(s) con discapacidad dedicado a la música de la "antara"

Las “antaras" duales de los nazcas.- A diferencia de los restos iconográficos y vasijas escultóricas de los Mochicas, en la sociedad Nazca no encontramos muchas evidencias de este uso, frente por ejemplo al uso colectivo o grupal que si observamos insistentemente; también el uso individual por parte de "músicos especiales" (fig. 21). Sin embargo, un par de evidencias pueden servirnos para concluir que esta forma de interpretación dual de las antaras eran conocidas por los nazcas empero es muy probable que hayan sido, como decía Cesar Bolaños, interdependientes entre instrumentos semejantes o iguales o en todo caso entre "octavas". Evidentemente la falta de evidencia instrumental que denote la existencia de instrumentos duales complementarios o interdependientes puede ser una contundente evidencia del desconocimiento de este tipo de antaras que en la actualidad conocemos como sikus.

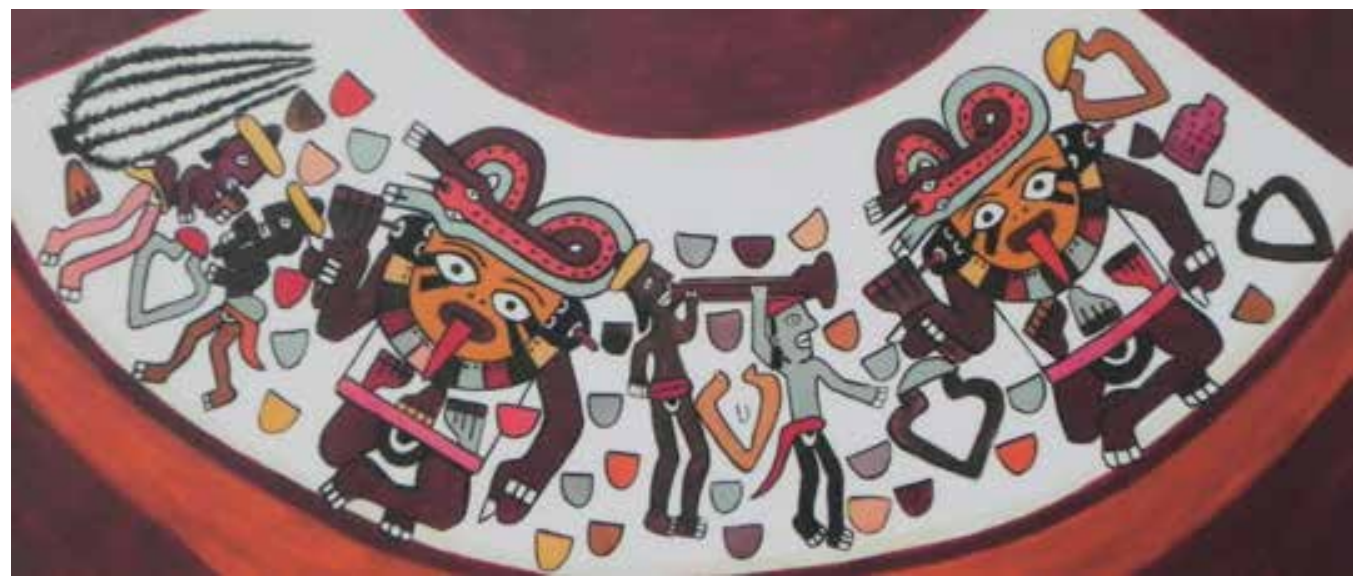

Fig. 22) Esta iconografía puede ser una evidencia de la ejecución dual entre dos "antaristas" nasquenses, estos parecieran "dialogar" tocando sus "antaras", instrumentos que parecen ser semejantes entre sí (Vasija del MNAAHP). 
Las orquestas de "antaras".- El carácter más importante para el presente caso será la evidencia de que los nazcas conformaban "orquestas" musicales en el pudieron haber participado varios músicos (decenas tal vez) de las formas colectivas que hoy podemos observar con los sikuris altiplánicos. Para ello debieron haber tenido grandes habilidades musicales que se debió iniciar con el largo proceso de construcción de las "antaras" como ya señalamos. De esta manera construyeron "juegos, familias o tamaños de antaras" usando patrones establecidos, el más conocido para nosotros son las "mitades" y los "dobles" para generar sonidos agudos y graves en proporciones geométricas exactas (octavas). Además de esto, la colectivizaron duplicando o triplicando cada tamaño de instrumento, logrando de seguro una espectacular orquesta musical. Sin duda, el hallazgo en la zona arqueológica de Cahuachi en los años 90 por el arqueólogo Orefici es muy significativo tanto por la cantidad de "antaras" como por el hallazgo de "antaras gigantes" (casi un metro de largo con más de una docena de tubos), estas al parecer fueron enterradas quebrándolas adrede en un gran ritual donde no habría estado exenta la música (Gruczinska 2014).

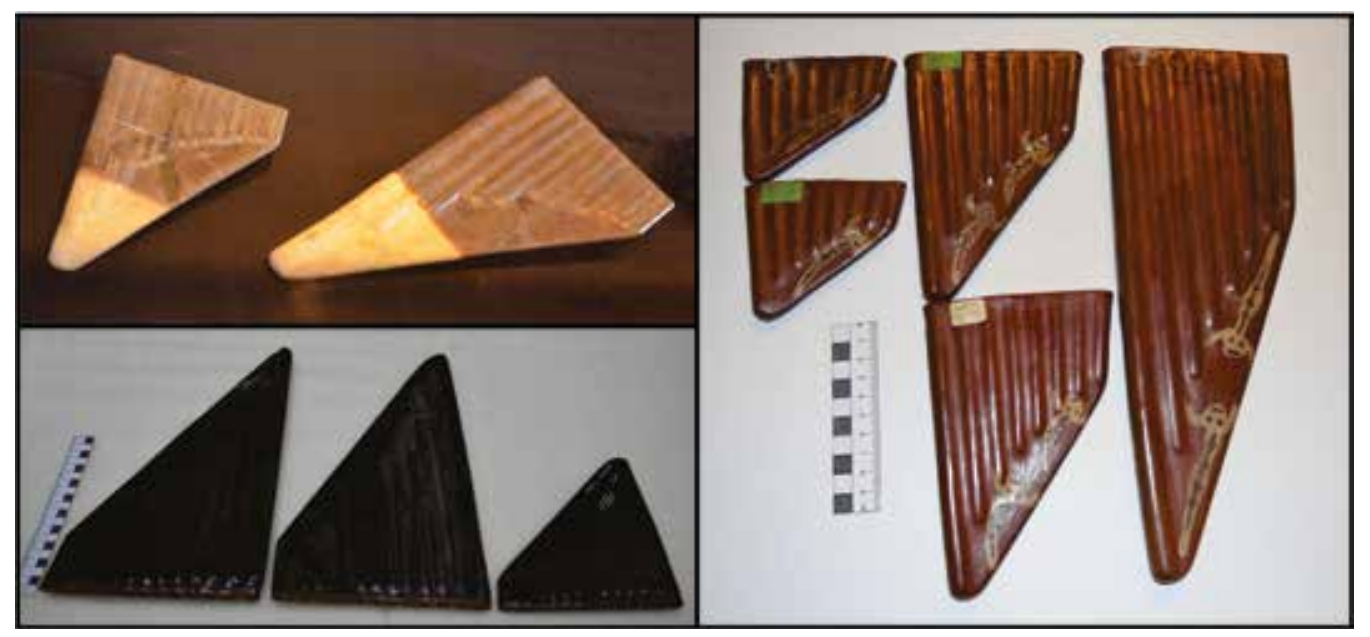

Fig. 23) Tres "conjuntos de antaras" que denotan un gran conocimiento musical pues definitivamente formaron grandes orquestas musicales, pues las "antaras" aquí presentadas sólo son las que se pudieron salvar de los saqueos de los "huaquedaores". 23a) MNAAHP, 23b) MAAUNMSM, 23c) Museo del BCR.

El conjunto de flautas de pan del BCR.- Veamos rápidamente cómo el conocimiento de un tipo universal de búsqueda sonora fue también utilizado por la sociedad Nazca: las mitades y los dobles, el uso de la matemática universal generó la construcción de este conjunto orquestal de "antaras" presentada a continuación. ${ }^{16}$ Las flautas de pan estudiadas forman parte de la colección del Museo del Banco Central de Reserva del Perú los cuales fueron adquiridos a un coleccionista privado hace un par de décadas y en la actualidad se encuentra en exhibición al público. Por las características pertenecerían al periodo de auge de esta sociedad, los instrumentos están construidos en cerámica (arcilla roja) sin mayor distinción o elegancia en los acabados como suelen ser algunas "antaras", evidentemente fueron concebidas para un trabajo específicamente musical (fig. 24). Una pequeña "lagartija" de color blanco pintada en las cinco piezas y en el mismo lugar, demuestran su pertenencia a esta familia de

16. Lo presentado aquí sobre las flautas de pan Nazca, es una apretada síntesis de un mayor trabajo organológico que venimos realizando con el músico Paul Huarancca Parco de esta y otros conjuntos de "antaras". 
"antaras" a un grupo musical. Todas poseen embocaduras ojivales en forma de anillos ovalados cuya función es la de ser "modificadores sonoros", pasan de producir timbres "borrascosos" (batimento) a timbres refinados. Las medidas físicas que dividen en partes iguales a los tres tamaños de "antaras" son corroborados con los sonidos que emiten cada una (nota musical) las cuales fueron medidas con "afinadores" convencionales en el momento de la inspección. Así obtenemos prácticamente dos tipos de precisiones: 1) Igualdad entre las "antaras" pequeñas (las llamaremos chilis) y de las "antaras" medianas (las llamaremos maltas), mientras que la tercera se encuentra sola y la llamaremos sanja ${ }^{17}$. 2) La "antara" grande (sanja) es el doble de las antaras medianas (maltas) y estas son a la vez de las pequeñas (chilis). A continuación detallamos las medidas y las notas de cada antara analizada:

Flauta de pan ACE 004 (denominaremos chili 1)

\begin{tabular}{|c|c|c|c|}
\hline Número de tubo (de menor a mayor) & Largo externo mm. & Largo interno mm. & Notas \\
\hline 1 & 27.05 & 24.57 & E7 -1 \\
\hline 2 & 28.50 & 26.54 & D\#7 - 77 \\
\hline 3 & 31.73 & 31.10 & D7 -44 \\
\hline 4 & 37.87 & 36.81 & B6 -9 \\
\hline 5 & 43.78 & 41.64 & A6 -2 \\
\hline 6 & 51.52 & 48.65 & G6 -46 \\
\hline 7 & 60.73 & 54.79 & E6 -7 \\
\hline 8 & 77.07 & 72.60 & C6 +28 \\
\hline
\end{tabular}

Flauta de pan RP 2745/92 (chili 2)

\begin{tabular}{|c|c|c|c|}
\hline $\begin{array}{c}\text { Número de tubo (de menor } \\
\text { a mayor) }\end{array}$ & Largo externo mm. & Largo interno mm. & Notas \\
\hline 1 & 25.56 & 24.63 & E7 -27 \\
\hline 2 & 30.29 & 27.82 & D\#7 -29 \\
\hline 3 & 34.26 & 31.41 & C\#7 -20 \\
\hline 4 & 38.23 & 36.97 & B6 -30 \\
\hline 5 & 44.81 & 41.04 & A6 +10 \\
\hline 6 & 51.23 & 48.80 & G6 -40 \\
\hline 7 & 61.65 & 58.84 & E6 -39 \\
\hline 8 & 76.40 & 74.60 & C6 +24 \\
\hline
\end{tabular}

17. Estamos usando los nombres distintivos casi universales del mundo de los conjuntos de flautas de pan del modelo siku, los mismos que consideran tres tamaños principales (de pequeño a grande, siempre en proporción de doble): chili, malta y sanja. 
Flauta de pan ACE 002 (malta 1)

\begin{tabular}{|c|c|c|c|}
\hline $\begin{array}{c}\text { Número de tubo (de menor } \\
\text { a mayor) }\end{array}$ & Largo externo mm. & Largo interno mm. & Notas \\
\hline 1 & 51.72 & 48.60 & F\#6 -26 \\
\hline 2 & 58.28 & 55.63 & E6 +20 \\
\hline 3 & 64.69 & 62.78 & D6 +40 \\
\hline 4 & 76.12 & 73.51 & C6 -26 \\
\hline 5 & 85.19 & 83.05 & A\#5 -20 \\
\hline 6 & 97.74 & 96.20 & G\#5 -30 \\
\hline 7 & 119.24 & 115.91 & F5 -35 \\
\hline 8 & 149 & 146.01 & C\#5 -30 \\
\hline
\end{tabular}

Flauta de pan ACE 003 (malta 2)

\begin{tabular}{|c|c|c|c|}
\hline $\begin{array}{c}\text { Número de tubo (de menor } \\
\text { a mayor) }\end{array}$ & Largo externo mm. & Largo interno mm. & Notas \\
\hline 1 & 51.09 & 48.32 & G6 -22 \\
\hline 2 & 57.72 & 55.74 & E6 -48 \\
\hline 3 & 65.52 & 63.05 & D\#6 -44 \\
\hline 4 & 76.20 & 73.54 & C6 -22 \\
\hline 5 & 85.28 & 83.57 & A\#5 - \\
\hline 6 & 100.04 & 96.88 & G\#5 -45 \\
\hline 7 & 118.58 & 116.69 & F5 -40 \\
\hline 8 & 150.10 & 146.68 & C\#5 -42 \\
\hline
\end{tabular}

Antara RP 2757/94 (sanja)

\begin{tabular}{|c|c|c|c|}
\hline $\begin{array}{c}\text { Número de tubo (de menor } \\
\text { a mayor) }\end{array}$ & Largo externo $\mathrm{mm}$. & Largo interno mm. & Notas \\
\hline 1 & 99.2 & 97.5 & $\mathrm{G} 5-10$ \\
\hline 2 & 113 & 112 & $\mathrm{~F} 5+21$ \\
\hline 3 & 128 & 125.5 & D\#5 +8 \\
\hline 4 & 151 & 147.5 & C\#5 -39 \\
\hline 5 & 172 & 166 & B4 -45 \\
\hline 6 & 198 & 194 & G\#4 -14 \\
\hline 7 & 239 & 234.5 & F4 -20 \\
\hline 8 & 302 & 296 & C\#4 -10 \\
\hline
\end{tabular}



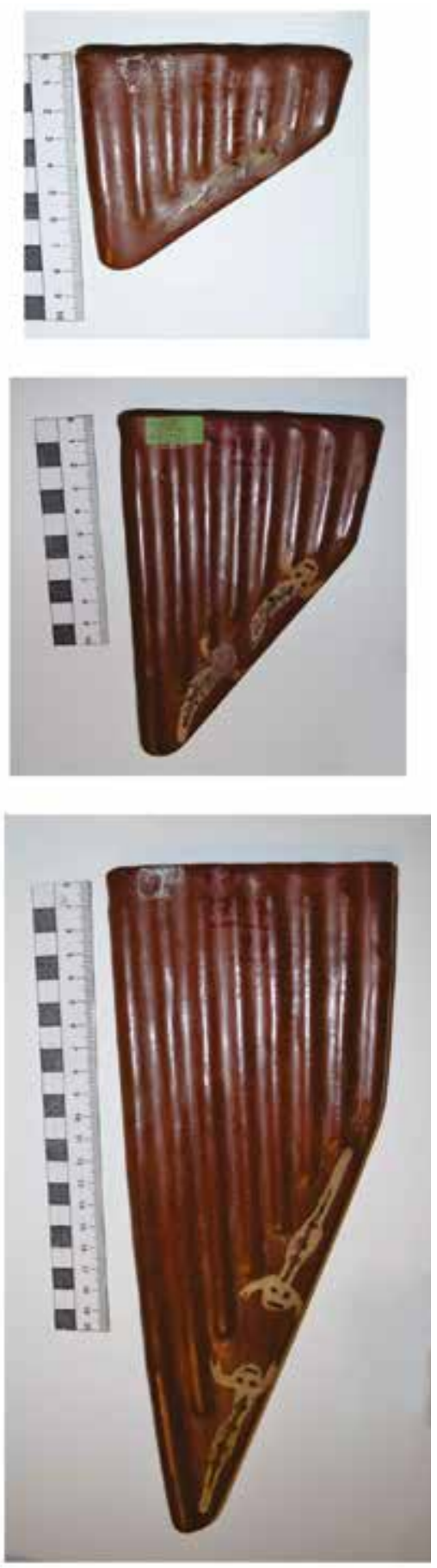

\begin{tabular}{|c|c|c|c|}
\hline $\begin{array}{c}\text { Número de } \\
\text { tubo (de menor } \\
\text { a mayor) }\end{array}$ & $\begin{array}{c}\text { Largo } \\
\text { externo } \\
\mathrm{mm} .\end{array}$ & $\begin{array}{c}\text { Largo } \\
\text { interno } \\
\mathrm{mm} .\end{array}$ & Notas \\
\hline 1 & 27.05 & 24.57 & $\mathrm{E7}-1$ \\
\hline 2 & 28.50 & 26.54 & $\mathrm{D} \# 7-17$ \\
\hline 3 & 31.73 & 31.10 & $\mathrm{D} 7-44$ \\
\hline 4 & 37.87 & 36.81 & $\mathrm{~B} 6-9$ \\
\hline 5 & 43.78 & 41.64 & $\mathrm{~A}_{6}-2$ \\
\hline 6 & 51.52 & 48.65 & $\mathrm{G}_{6}-46$ \\
\hline 7 & 60.73 & 54.79 & $\mathrm{E}_{6}-7$ \\
\hline 8 & 77.07 & 72.60 & $\mathrm{C}_{6}+28$ \\
\hline
\end{tabular}

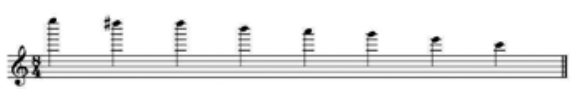

\begin{tabular}{|c|c|c|c|}
\hline $\begin{array}{c}\text { Número de } \\
\text { tubo (de } \\
\text { menor a } \\
\text { mayor) }\end{array}$ & $\begin{array}{c}\text { Largo } \\
\text { externo } \\
\text { mm. }\end{array}$ & $\begin{array}{c}\text { Largo } \\
\text { interno } \\
\text { mm. }\end{array}$ & Notas \\
\hline 1 & 51.72 & 48.60 & F\#6 -26 \\
\hline 2 & 58.28 & 55.63 & E6 +20 \\
\hline 3 & 64.69 & 62.78 & D6 +40 \\
\hline 4 & 76.12 & 73.51 & C6 -26 \\
\hline 5 & 85.19 & 83.05 & A\#5 -20 \\
\hline 6 & 97.74 & 96.20 & G\#5 -30 \\
\hline 7 & 119.24 & 115.91 & F5 -35 \\
\hline 8 & 149 & 146.01 & C\#5 -30 \\
\hline
\end{tabular}

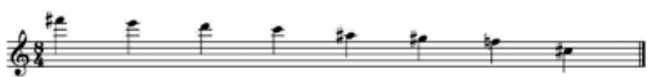

\begin{tabular}{|c|c|c|c|}
\hline $\begin{array}{c}\text { Número de } \\
\text { tubo (de } \\
\text { menor a } \\
\text { mayor) }\end{array}$ & $\begin{array}{c}\text { Largo } \\
\text { externo } \\
\text { mm. }\end{array}$ & $\begin{array}{c}\text { Largo } \\
\text { interno } \\
\text { mm. }\end{array}$ & Notas \\
\hline 1 & 99.2 & 97.5 & G5 -10 \\
\hline 2 & 113 & 112 & F5 +21 \\
\hline 3 & 128 & 125.5 & D\#5 +8 \\
\hline 4 & 151 & 147.5 & C\#5 -39 \\
\hline 5 & 172 & 166 & B4 -45 \\
\hline 6 & 198 & 194 & G\#4 -14 \\
\hline 7 & 239 & 234.5 & $\mathrm{~F}_{4}-20$ \\
\hline 8 & 302 & 296 & C\#4 -10 \\
\hline
\end{tabular}

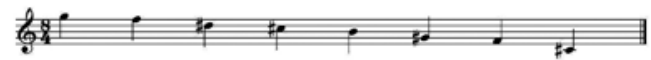




\section{AgRAdecimientos}

Hacemos llegar un agradecimiento especial al director del Museo de Arqueología y Antropología de la UNMSM por haber tramitado el permiso para analizar las piezas arqueológicas ("antaras") del Museo del Banco Central de Reserva del Perú. El registro y las transcripciones estuvo a cargo del músico Paul Huarancca Parco y del autor del presente artículo.

\section{Bibliografía}

\section{ARETZ, Isabel}

1991 Historia de la Etnomusicología en América Latina (Desde la época precolombina hasta nuestros días). FUNDET, CONAC, OEA. Caracas, Venezuela.

\section{BELLENGUER, Xavier}

2007 El espacio musical andino, modo ritualizado de producción musical en la isla de Taquile y la región del lago Titicaca. IFEA (Instituto Francés de Estudios Andinos). Lima.

\section{BOURGET Steve}

2007 Morir para gobernar sexo y poder en la sociedad Moche. Museo de Arte Precolombino de Chile.

BLACKING, John

1973 ¿Hay música en el hombre? Alianza Editorial S.A. Madrid.

BOLAÑOS V., César

1988 Las antaras nazca: historia y análisis. Publicación del INDEA. Lima.

2007 Origen de la música en los Andes. Instrumentos musicales, objetos sonoros y músicos de la Región Andina precolonial. Fondo Editorial del Congreso del Perú. Lima.

CIVALLERO, Edgardo

2012 “Flautas de Pan”. En: Revista Folklore, fundación Joaquín Díaz. Edición digital Anuario 2012. En, http://www.funjdiaz.net/folklore/anuarios/rf2012.pdf

FERNÁNDEZ ALVARADO, Julio

2014 "El mono: símbolo de la fertilidad en el antiguo Perú". Revista TZHOECOEN. Universidad Señor de Sipán.

FORTÚN, Julia Elena

1969-70. “Aerófonos prehispánicos andinos”. En: Folklore Americano. Años XVII - XVIII. № 16. p. 49 - 77. Lima.

GERARD A., Arnaud

1999 “Acústica de las siringas andinas de uso actual en Bolivia”. Informe de investigación. Universidad Autónoma Tomas Frías. Potosí, Bolivia.

2004 "Interpretación acústica del ayarachi lítico "Yura" de los Museos Charca". En: Jornadas Arqueológicas. 1ra versión. Sucre, Bolivia. Universidad San Francisco Xavier de Chuquisaca.

2009 "Sonidos "ondulantes" en silbatos dobles arqueológicos: ¿Una estética ancestral reiterativa?” Revista Española de Antropología Americana, vol. 39, № 1. España.

2013 "Sonido tara en pifilcas arqueológicas provenientes de Potosí". En: Arqueo/antropológicas, Revista de la Universidad Mayor de San Andrés. Año 3, N 3. Cochabamba, Bolivia. 


\section{GUTIÉRREZ C., Ramiro y Edwin IVÁN}

2009 Música, Danza y Ritual en Bolivia: una aproximación a la cultura musical de los andes, Tarija y el chaco boliviano. FAUTAPO, La Paz, Bolivia.

GOLTE, Jürgen

2009 Moche: Cosmología y sociedad, una interpretación iconográfica. IEP - CBC. Lima.

GRUSZCZYÑSKA, Anna

2009 “Variedad sonora de las antaras Nasca: ¿Un caos o el sistema?” Revista Española de Antropología Americana vol. 39, $\mathrm{N}^{\circ} 1$.

2014 Detrás del silencio: la música en la cultura Nasca. Fondo Editorial de la Pontificia Universidad Católica del Perú.

HOCQUENGHEM, Anne

1987 Iconografía Mochica. PUCP Fondo Editorial. Lima.

LARCO HOYLE, Rafael

1965 CHECAN. Editorial Nagel

\section{MAKOWSKI, Krzystof}

2010 “Las relaciones entre Virú y Moche desde la perspectiva del Alto Piura", en: Rubén Romero y Trine Pavel (eds.), Arqueología del Perú: 74-014, Lima.

OREFICI, G. y A. Drusini

2003 Nasca. Hipótesis y evidencias de su desarrollo cultural. Centro Italiano Studi e Ricerche Archeologiche Precolombiane (CISRAP), Lima.

PÉREZ DE ARCE, José

1993 “El Siku”. En Revista Andina N²2. Cusco.

2004 “Análisis de las cualidades sonoras de las botellas silbadoras prehispánicas de los Andes". Boletín del Museo Chileno de Arte Precolombino, № 09.

SÁNCHEZ H., Carlos

2013 La flauta de pan andina: los grupos de sikuris metropolitanos. Fondo editorial UNMSM. Lima.

TELLO, Julio C. y Toribio MEJíA XESSPE

1979 Paracas: Cavernas y Necrópolis II Parte. UNMSM. Lima.

TELLO, Julio C.

(1999) Cuadernos de Investigación del Archivo Tello Nº1, 02 y 03. Museo de Arqueología y Antropología, UNMSM. Lima.

VALENCIA CH., Américo

1989 El siku o zampoña. Perspectivas de un legado de un legado musical preincaico y sus aplicaciones en su desarrollo de la música peruana. CIDEMP. Artex Editores. Lima. 